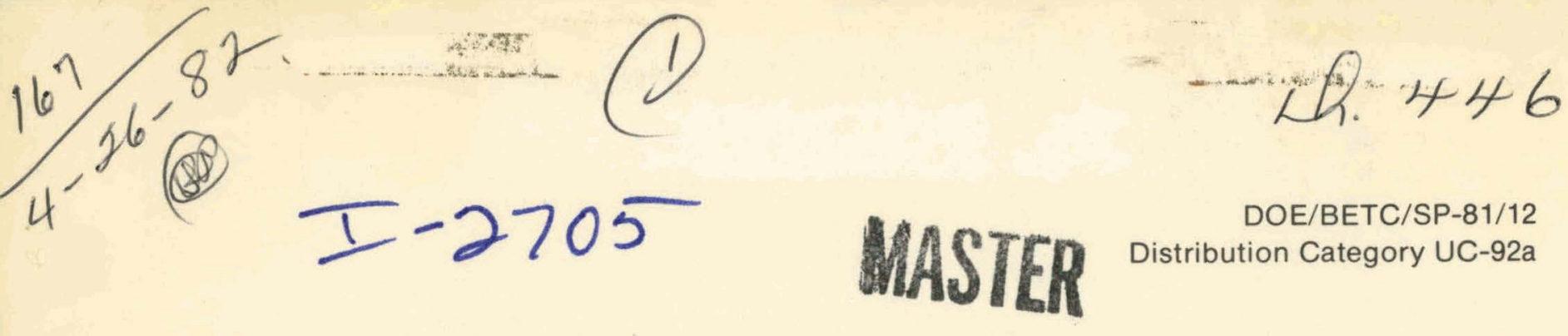

Frontier Area Research Projects

\title{
RESEARCH PROJECTS NEEDED FOR EXPEDITING DEVELOPMENT OF DOMESTIC OIL AND GAS RESOURCES THROUGH ARCTIC, OFFSHORE, AND DRILLING TECHNOLOGY
}



This Document Contains the Findings of the January $5-7,1981$ Workshop

BARTLESVILLE ENERGY TECHNOLOGY CENTER

U.S. DEPARTMENT OF ENERGY

BARTLESVILLE, OKLAHOMA 74005 


\section{DISCLAIMER}

This report was prepared as an account of work sponsored by an agency of the United States Government. Neither the United States Government nor any agency Thereof, nor any of their employees, makes any warranty, express or implied, or assumes any legal liability or responsibility for the accuracy, completeness, or usefulness of any information, apparatus, product, or process disclosed, or represents that its use would not infringe privately owned rights. Reference herein to any specific commercial product, process, or service by trade name, trademark, manufacturer, or otherwise does not necessarily constitute or imply its endorsement, recommendation, or favoring by the United States Government or any agency thereof. The views and opinions of authors expressed herein do not necessarily state or reflect those of the United States Government or any agency thereof. 


\section{DISCLAIMER}

Portions of this document may be illegible in electronic image products. Images are produced from the best available original document. 


\section{DISCLAIMER}

"This book was prepared as an account of work sponsored by an agency of the United States Government. Neither the United States Government nor any agency thereof, nor any of their employees, makes any warranty, express or implied, or assumes any legal liability or responsibility for the accuracy, completeness, or usefulness of any information, apparatus, product, or process disclosed, or represents that its use would not infringe privately owned rights. Reference herein to any specific commercial product, process, or service by trade name, trademark, manufacturer, or otherwise, does not necessarily constitute or imply its endorsement, recommendation, or favoring by the United States Government or any agency thereof. The views and opinions of authors expressed herein do not necessarily state or reflect those of the United States Government or any agency thereof."

Available from the National Technical Information Service, U.S. Department of Commerce, Springfield, Virginia 22161.

\section{NTIS price codes \\ Paper copy: $\quad \$ 14.00$ \\ Microfiche copy: $\$ 3.50$}




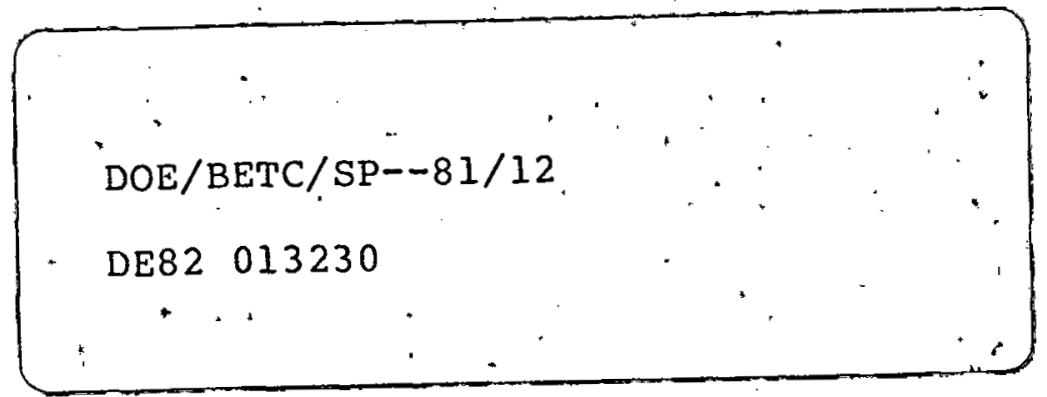

DOE/BETC/SP-81/12

Distribution Category UC-92a

Frontier Area Research Projects

RESEARCH PROJECTS NEEDED FOR EXPEDITING

DEVELOPMENT OF DOMESTIC OIL AND GAS RESOURCES

THROUGH ARCTIC, OFFSHORE, AND DRILLING TECHNOLOGY

This report was compiled and edited by the

Bartlesville Energy Technology Center

with assistance from support contractor

Keplinger \& Associates, Inc.

Safron Canja, Program Manager

Frontier Area Research

U.S. DOE Headquarters Washington, D.C. -

C. Ray Williams, Project Manager

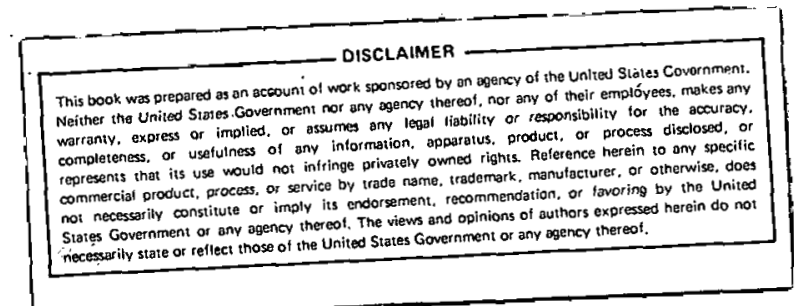
Frontier Area Research

Bartlesville Energy Technology Center Bartlesville, Oklahoma

This document contains the findings of the January 5-7, 1981, industry and government workshop

which covered the research needs of

Arctic, Offshore, and Drilling Technology.

Date Published-April 1982

UNITED STATES DEPARTMENT OF ENERGY 


\section{FOREWORD}

The comments and information contained herein are the opinion of the workshop participants and are not intended to represent either national or DOE policy. The research and development projects described were determined by the needs of the petroleum industry as seen by oilfield professionals. Obviously, the thrust and scope of the DOE Fossil Energy Division program in Frontier Area Research (FAR) will be primarily determined by federal budget allocations. The amount of work performed under that budget will be extended because, as in the past, the FAR program will continue to encourage and pursue joint-development efforts with private industry and other government agencies whenever feasible.

The DOE/FAR program will continue to work closely with the Department of Interior (USGS and BLM) to support leasing activities in the offshore and arctic areas. This support will be through the use of DOE's instrumentation research capabilities (from DOE's National Laboratories) to develop advanced methods to characterize the environment. This expertise will be to determine information such as the following:

$\begin{array}{ll}0 & \text { Subsea soil stability and strength measurements } \\ 0 & \text { Ice strength and fracture mechanics } \\ 0 & \text { Ice pack movement and detection } \\ 0 & \text { Underwater acoustical transmission } \\ 0 & \text { Wave/current measurements } \\ 0 & \text { Seafloor earthquake measurements }\end{array}$

The FAR Program will also continue to work closely with various committees of the National Science Foundation (NSF), the Marine Board and the Geological Sciences committee of the National Research Council, and other committees of the Academy of Engineering and Academy of Science to identify and jointly support the $R \& D$ required to advance the state-of-the-art of drilling and exploration in the frontier areas.

Safron Canja

Program Manager

Frontier Area Research

U.S. UUE Headquarters

Washington, D.C.
C. Ray Williams

Project Manager

Frontier Area Research

Bartlesville Energy Technology Center

Bartlesville, OK 
Purpose and Acknowledgement..........................

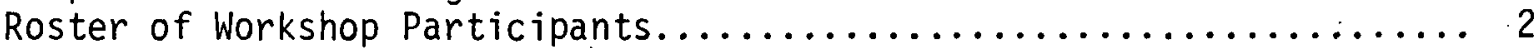

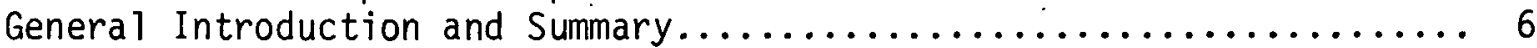

General Research Roles of Industry and Government.............. 8 Major Program Elements

Arctic Research Section............................ 9

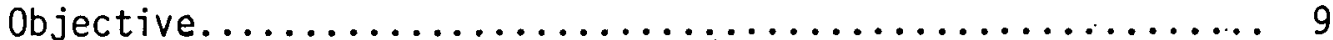

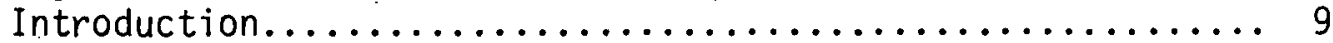

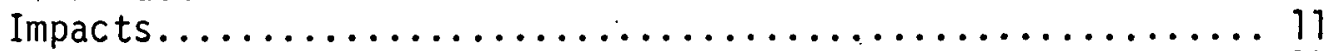

Government Research Role and Needs................. 11

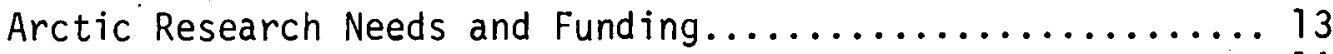

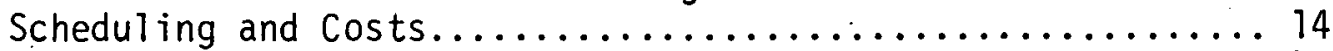

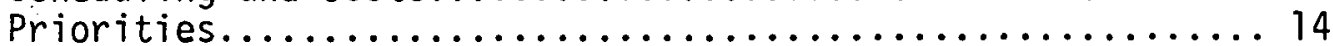

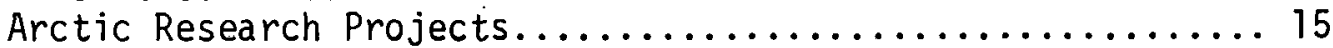

Ice Characteristics....................... 16

Mechanical Properties.................... 16

Geometry and Structure of Ice Packs and Ridges.... 18

Dynamics........................... 19

Instrumentation Development............... 21

Ice Accretion and Corrosion Protection.......... 22

Ice/Structure Interaction.................... 23

Ice Behavior Against Structures.............. 23

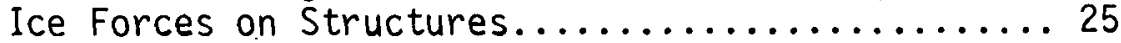

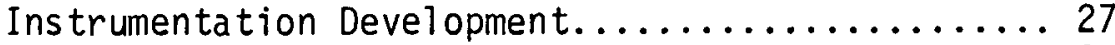

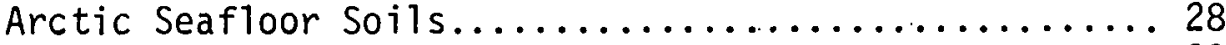

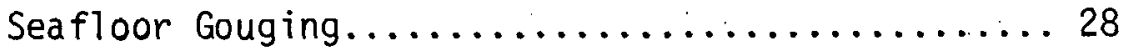

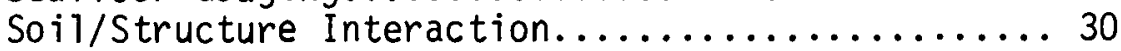

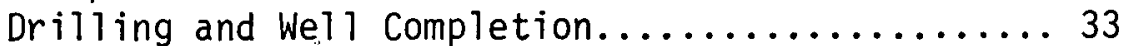

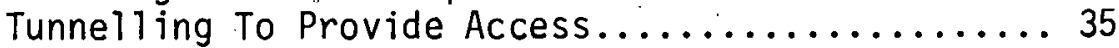

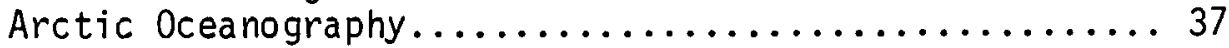

Ice Cover Effects on Wave Generation and Maximum

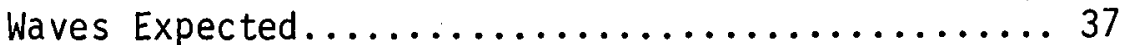

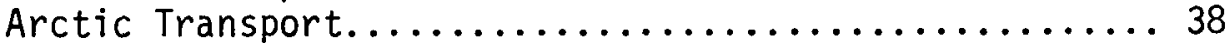

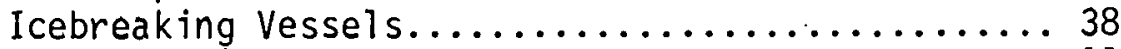

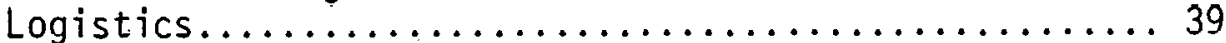

Offshore Research Section.......................... 40

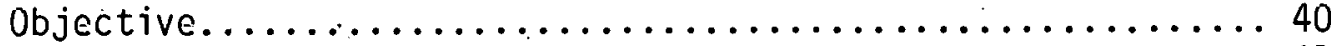

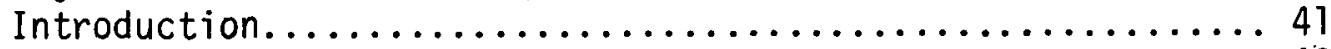

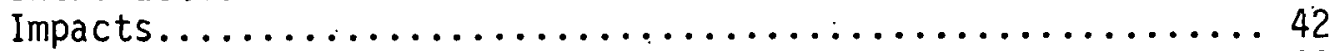

Government Role in offshore R\&D.................. 43

Offshore Research and Development Needs.............. 44

Definition of Proposed Program................... 47

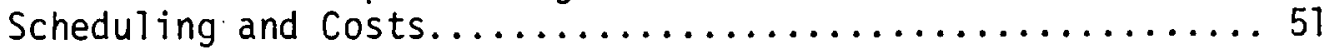

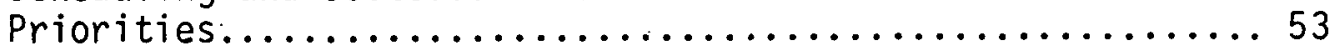

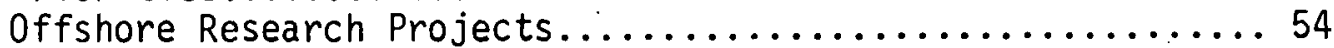

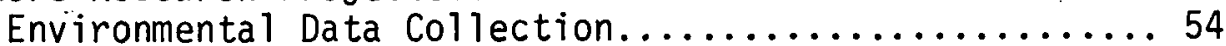

Meteorologic and Oceanographic Data Reduction....... 57

Sea Floor Instrumentation...................... 59

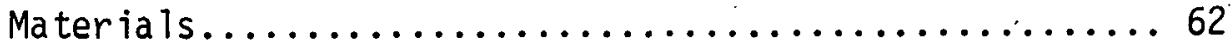


Weight Reduction....................... 62

Corrosion and Fatigue..................... 64

Deep. Water Technology........................ 67

Supporting Research......................... 69

Causes and Behavior of Internat Waves.......... 69

Development of Marginal Fields................ 70

Data Telemetry Projects................... 71

Drilling Research Section.............................. 75

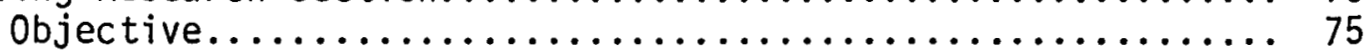

Background....................................... 75

Introduction................................... 76

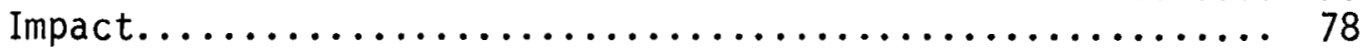

Drilling Research Needs.......................... 78

Research Role of the Drilling Industry................ 80

Government Role in Drilling Research.................. 81

The Program and Funding............................ 83

Scheduling and Costs.......................... 83

Priorities............................... 85

Drilling Research Projects With A Government Role......... 87

Conventional Technology........................ 87

Rock Mechanics....................... 87

Earth Stress....................... 87

Borehole Stability.................... 90

Rock Cutting Phenomena................. 91

Fluid Systems............................. 93

Fluid Dynamics.......................... 93

Drilling Systems Ana iyses.................... 94

Pore Pressure and Fracture Gradient Data

Analyses............................ 96

Post Well Drilling Data Analyses for

General Correlations..................... 97

Magnetic Anomaly Data................... 98

Driil String Analysis.................... 99

System Integration Analysis................ 100

Materials.............................. 101

Alternative to Strategic Materials Used In

Drilling for Petroleum or Other Energy

Resources........................... 101

High Temperature Elastomers.............. 103

Instrumentation......................... 104

Rock Properties from Logs................ 104

Automatic Drill-Pipe Inspection........... 106

Surveying Accuracy.................... 107

Downhole/Realtime Data Collection and

Analysis............................ 108

Coal Seam Sensor....................... 109

Sensor Concepts........................ 110

Design and Development...................... 111

Improved Seals........................ 111

Improved Coring System................. 112

Cementing High-Angle Holes............... 113

Advanced Drilling Systems........................ 114

Electrodril............................... 114

Horizontal Drilling........................... 115

Jet Cutting Driliing........................ 116

Advanced Directional Drilling System............. 118 
Environmenta 7 Research......................... 121

Safety Research............................. 122

Drilling Research Projects for Industry Alone........... 123

Conventional Technology........................ 124

Fluid Systems.............................. 124

'Solids Control....................... 124

Non-Clay Fluids....................... 124

Cutting Transport................... 125

Fluid Abrasion......................... 126

Drilling Systems Analyses.................. 127

Production Damage.................. 127

Materials............................ 127

Drill Pipe Coatings....................... 127

High Performance Lubricants for Downhole

Tools.............................. 128

Alternate Cutting Materials.............. 129

Corrosion Related Materials Problems........ 130

Instrumentation....................... 132

Downhole MWD/Logging................... 132

Design and Development.................... 133

Improved Bits....................... 133

We 17 bore/Cement/Casing/Design............ 135

Directional Drilling Systems.............. 136

Advanced Drilling Systèms.................... 137

Flexible Drillstring Drill................. 137

Deep Fluid Motor........................ 138

Safety................................... 140

$\mathrm{H}_{2} \mathrm{~S}$ Detection............................ 140

Environmental............................... 141

$0 i 1 /$ Water Separation........................... 141

Cuttings Cleaning ( $0 i 1$ Mud) $\ldots \ldots \ldots \ldots \ldots \ldots \ldots, 142$

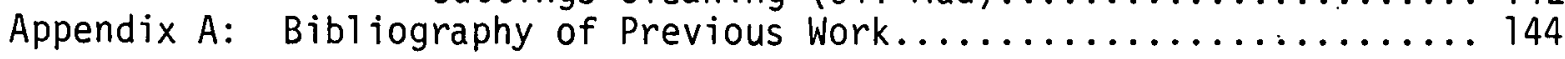




\section{PURPOSE AND ACKNOWLEDGMENT}

This document contains the research projects which were identified at an industry-government workshop on Arctic, Offshore, and Drilling Technology (AODT) held at Bartlesville Energy Technology Center, January 5-7, 1981.

The purpose of the workshop was to identify those problem areas where government research could provide technology advancement that would assist industry in accelerating the discovery and development of U.S. 0il and gas resources. The workshop results are to be used to guide an effective research program. The workshop identified and prioritized the tasks that need to be implemented.

The workshop participants were divided into three work groups. A special acknowledgment is due for Robert Huggins of Amoco, Elard Haden of Conoco, and W. M. Sackinger of the University of Alaska. They served as chairmen for the Drilling, Offshore, and Arctic groups, respectively. They also provided excellent reviews of the draft.

All of the projects listed in the Arctic and Offshore sections were selected as appropriate for a Department of Energy (DOE) research role. The drilling projects identified as appropriate only for industry research have been separated in the Drilling section of this report.

A roster of the workshop participants is presented below. Their efforts toward identification of the research needed to accelerate development of domestic resources is much appreciated. 


\section{ROSTER OF AODT WORKSHOP PARTICIPANTS \\ Drilling Research Group Roster}

Robert Huggins (Chairman)

Drilling Research Director

Amoco Production Co.

Tulsa, OK

K. 0. Taylor

Research Director

NL Industries

Humble, TX

R. W. Nicholson

Geothermal, 0il \& Gas Drilling Consulting \& Well Testing

Well Production Testing

Costa Mesa, CA

T, E. Watkins

Mgr., Drilling \& Completion Research

Mobil

Dallas, TX

Joe R. Tillerson

Supvr., Drilling Research

Saridia Laboratories

Albuquerque, NM

\section{Alan McFall}

Drilling Research

Sandia Laboratories

Albuquerque, NM

Bill Livesay

Livesay Consultants

Cardiff, $\mathrm{CA}$

John C. Schillo

Operations Manager

CER Corporation

Las Vegas, NV
Harold D. Shoemaker

Project Manager, UGR Drilling

Technology

DOE/METC

Morgantown, WV

Joseph W. Neudecker, Jr.

Drilling R\&D (directional \& instrumentation)

Los Alamos Scientific Lab.

Los Alamos, NM

LeRoy R. England

Consultant

Keplinger \& Associates

Bartlesvitie, OK

Ed Moerbe

Mgr., Operations Engineering

Dresser Security Div.

Houston, TX

Walter E. Littmann

Rock Bits and Drilling Tools

Research \& Engineering

Dresser Industries-Security Div.

Dallas, TX

C. Ray Williams

Drilling Research

DOE/BETC

Bartlesville, OK

R. J. Duran

Drilling Field Supt.

Loffland Bros. Co.

Tulsa, OK

Annie Laurie Ellison

Keplinger \& Associates

Albuquerque, NM 


\section{Offshore Group Roster}

Elard Haden (Chairman)

Conoco, Inc.

Ponca City, OK

Fränk Manning

Mobil Oil Corp.

David H. Duke

DOE HQ

Washington, D.C.

Dallas, TX

Paul Teleki

USGS/Marine Geology

Reston, VA

George Bruce

Exxon Production Research Co.

Houston, TX

Paul L. Gassett

Gulf 0 il Corp.

Houston, TX

Sidney Green

Sam J. Poythress, Jr.

Terra Tek

Salt Lake City, UT

Keplinger \& Associates, Inc.

Bartlesville, OK

Richard Giangerelli

R. Michael Peterson

U. S. Geological Survey

Keplinger \& Associates, Inc.

Reston, VA

Bartlesville, OK

Eric W. Reece

Sandia National Labs

Hap Stoller

Albuquerque, NM

Sandia National Laboratory

Albuquerque, NM

Roy Portèr

DOE/BETC

Bartlesville, OK

Department of Energy

Supervision \& Support Service

DOE - Headquarters

Bennie DiBona

George Stosur

Safron S. Canja
DOE - Bartlesville, OK

Roc Castellano

Alex Crawley

Robert Folstein

Robert Johansen

Harry Johnson

Bill Linville

Don Ward

Barbara Barnett 
Rich Schmidt

Sandia Laboratories

Albuquerque, NM

James M. Drewry

McDermott, Inc.

New Orieans, LA

Bert Smith

Phillips Petroleum Co.

Bartlesville, OK

Al Sutko

Conoco, Inc.

Ponca City, OK
W. M. Sackinger (Chairman)

Geophysical Institute

University of Alaska

Fairbanks, AK

Bruce Baker

Office of the Governor

State of Alaska

Juneau, AK

Sam J. Poythress, Jr.

Keplinger and Associates

Bartlesville, OK

Arctic 0 il and Gas Recovery Research Planning Workshop June 30-July .2, 1980, Albuquerque, NM*

K. R. Croasdale

Dome Petroleum, Ltd.

P.0. Box 200

Calgary Alberta,

CANADA

Malcolm A. Goodman

Enertech Engrg. \& Research Co.

2727 Kirby, Suite 201

Houston, TX 77098

John Kreider

She 11 Development Co.

P. 0. Box 481

Houston, TX 77001

R. L. MCNeill

Sandia National Labs

Division 4739

Albuquerque, NM 87185

Robert Prindle

Sandia National Labs

Division 4739

Albuquerque, NM 87185

Rich Schmidt

Sandia National Laboratory

Division 4733

Albuquerque, NM 87185
Rod Edwards

ARCTEC Canada Ltd.

311 Leggett Drive

Kanata, Ontario,

CANADA K2K-1K3

Sandra Green

Sandia National Labs

Division 4739

Albuquerque, NM 87185

L. B. Karp

100. Tres Mesas

Orinda, CA 94563

J. F. Prince

Exxon Production Research

P.0. Box 2189

Houston, TX 77001

W. M. Sackinger

Geophysical Institute

University of Alaska

Fairbanks, AK 99701

Carl Schuster

Sandia National Laboratory

Division 4733

Albuquerque, NMi 87185 
Eric Reèce

Sandia National Laboratory

Division 4733

Aibuquerque, NM 87185

Paul Teleki

Office of Marine Geology

U.S. Geological Survey

Reston, VA 22092

W. F. Weeks

USA Cold Regions Research and Engineering Laboratory

Box 282

Hanover, NH 03755
Alex Slocum

7979 Westheimer Road

Apt. U-136

Houston, TX 77063

Robert E. Smith

ARCO 0 il \& Gas

P.0. Box 2819

Dallas, TX 75221

Sam Varnado

Sandia National Laboratory

Division 4741

Albuquerque, NM 87185

C. Ray Williams

DOE/BETC

P.0. Box 1398

Bartlesville, OK 74003

* Much of the program planning in the Arctic section of this document was taken from the report of this previous workshop held by DOE at Sandia National Laboratories, June 30-July 2, 1980. 


\section{COMPREHENSIVE RESEARCH PROGRAM FOR \\ ARCTIC, OFFSHORE, AND DRILLING TECHNOLOGY}

\section{I. GENERAL INTRODUCTION AND SUMMARY}

This is a research program planning document which updates the scope and direction of the previous Drilling and Offshore Technology Program to also include Arctic Research and which identifies the needed research work in the three areas. The budget for the previous effort has been much too small to encompass all of the needed work.

It is now clear that the United States must reduce oil imports to an acceptable level and move toward energy self-sufficiency. The Department of Energy has mounted vigorous research efforts toward development and expansion of all known energy sources, both conventional and unconventional. Many of these efforts focus on long-term research that will have little impact until the 1990-2000. time frame. One research area which can have a significant impact in the immediate future, namely faster development of conventional oil and gas domestic resources, is associated with advanced Arctic, Offshore, and Drilling Technology (AODT) research. Advanced AODT research can remove some the technological constraints restricting development of domestic oil and gas resnurces.

The most significant research needs which can accelerate the rate of domestic resource development for the three research areas are listed below. A11 are frontier areas where current technology is borderline or inadequate.

Arctic: Characterize the environment of arctic seas, ice and soils.

Offshore: Develop an Offshore Continental Shelf (OCS) engineering data base and the advanced technologies required for deep water operations. 
Drilling: Develop a better understanding of the physical processes involved in drilling and evaluating advanced drilling concepts and systems.

On January 5-7, 1981, an Arctic, Offshore, and Drilling Workshop was held at the Bartlesville Energy Technology Center, Bartlesville, Oklahoma. The participants were mainly from the petroleum industry, supported by representatives from the U.S. Geological survey (USGS), DOE, and National Laboratories. In total, 23 members of private industry representing 20 firms participated in this workshop. In addition, the results of an earlier workshop on Arctic research held in. June 1980 at Albuquerque, New Mexico, was reviewed and revised. The earlier workshop included 19 participants from industry, government and National Laboratories. The purpose of the workshop was to define those work areas where government research was most needed to accelerate production of domestic oil and gas. A chairman from industry was selected to lead each group and numerous research activities were identified. The driling group also identified certain research areas as appropriate only for industry performance. The workshop results will be the base text for future work performed under the AODT Program.

Funding requirements for performing the first five years' work identified by the workshop participants is tabulated below. The tabulation assumes that all needed projects begin at the same time and run concurrently from FY 83. Programmatically, that is impractical, considering funding limitations; but the data are shown here because the magnitude of funding needed reflects the immediate needs for technology advancement and engineering data defficiencies. 


$\begin{array}{lcccccc}\begin{array}{l}\text { Technology } \\ \text { Area }\end{array} & \frac{83}{15.8} & \frac{84}{15.5} & \frac{85}{15.2} & \frac{86}{13.7} & \frac{87}{13.1} & \frac{5 \text { Year Plan }}{73.3} \\ \begin{array}{l}\text { Arctic } \\ \text { Offshore }\end{array} & 14.2 & 14.3 & 14.2 & 9.6 & 9.4 & 61.7 \\ \text { Drilling } & 7.4 & \underline{11.1} & \frac{12.7}{42.1} & \frac{9.3}{32.6} & \frac{7.3}{29.8} & \frac{47.8}{182.8}\end{array}$

Most of the proposed projects would be completed within five years after. each begins. However, some direly needed data bases should continue for several more years. It is envisioned that the AODT Program should be completed by 1992 when alternative energy sources have begun to have a significant impact. The only continuous phase of the program is the updating of data bases.

Each of the three work areas should employ a program advisory council consisting of experts from industry, caademia, and government. All projects would be annually reviewed and evaluated as to progress, pertinence, and probable success. This would ensure an effective, coordinated program and also serve as one means of technology transfer.

IV. GENERAL RESEARCH ROLES OF INDUSTRY AND GOVERNMENT

The research needs and roles of industry and government have distinct inherent differences. Traditionally, industry performs short-term, low-risk research that will provide an early payout, while government agencies must envision long-term needs and advance those technologies which will be needed in the future. The governmental research should be in high-risk and/or basic research areas rarely addressed by industry. Any research program conducted by the government should not duplicate research and development efforts of private industry, nor reduce the incentives for industry to conduct private research, except where government needs may exceed those of private industry. Specific roles are identified in each section. 


\section{MAJOR PROGRAM ELEMENTS}

\subsection{ARCTIC RESEARCH}

There has been very little DOE effort in this area. Much basic knowledge is needed that will benefit all involved parties..

\subsection{Objective:}

The overall objective for Arctic research is to accelerate development of domestic $0 i 1$ and gas resources in Arctic areas. However, some secondary objectives establishing the program methodology are as follows:

1. Advance knowledge through characterization of Arctic environment.

2. Provide basic research necessary to induce technology development suitable for the harsh environment.

3. Ensure that technology is environmentally acceptable.

4. Enhance production economics which provide additional incentive.

\subsection{Introduction:}

There is a great lack of basic knowledge regarding drilling and producing oil and gas wells in the Arctic environment. It is difficult to operate in such a harsh, undefined environment without adequate research knowledge. However, oil operators recognize this and operate at the maximum state-of-the-art to achieve safety and efficiency. They design structures with high safety factors to compensate for the lack of basic engineering data because the benefits and production potential are tremendous and the resources need to be developed. These resources are the most favorable source of usable "near-term" energy available to the United States.

Seventy percent of America's undiscovered recoverable offshore oil resources are estimated in U.S. Geological Survey Circular 725 to lie 
within the Continental Shelf of Alaska's coast. . This consists of 19 billion barrels of $0 i 1$ and compares with a current annual production of about 2.2 billion barrels from the contiguous states and adjacent submerged lands. Sixty percent of the nations's undiscovered recoverable offshore gas resources also lie off Alaska's coast. 'These estimates are based on averaging the 5 and 95 percent probability levels.

The vast majority of Alaska offshore resources lie beneath the waters (and ice) of the Beaufort, Chukchi, and Bering Seas. These estimated resources have become a principal focus in this nation's effort to reduce its dependence on foreign petroleum supplies in favor of domestic production. Commensurate with this goal, the Department of the Interior has scheduled 14 initial oil and gas lease sales in these frontier areas during the period 1982 through 1986. Moreover, federal onshore petroleum development is scheduled to occur in the National Petroleum Reserve - Alaska (NPR-A).

Although possessing a significant proportion of estimated U.S. petroleum resources, these frontier areas present severe physical and climatological conditions and pose some of the most serious technological challenges ever experienced in the field of petroleum exploration and production. It is imperative that the technology employed in the Arctic reflect the most advanced state-of-the-art possible to ensure the safe and timely availability of petroleum products.

It was in recognition of this lack of knowledge and engineering data that the federal government scheduled its 1985 oil and gas leasing 
in the Chukchi Sea..."contingent upon a reasonable assumption that technology will be available for exploration and development of the tracts included in the sale." Implementation of this proposed work can assist in obtaining the information needed to develop the technology.

Timely production of the nation's domestic petroleum resources requires, therefore, that technological research in the Arctic be given high national priority. The achievement of this essential research will require the combined and complementary efforts of both the petroleum industry and those federal agencies whose missions relate to providing petroleum resources for the American public. This document identifies the types of investigations which should be addressed over the next five- to ten-year period.

\subsection{Impacts:}

Commensurate with the stated objective, performance of Arctic research will expedite the development of Arctic resources. Some of the impacts or benefits which can result from a concerted focus on Arctic technology research are the following:

1. Domestic supply of petroleum becomes more reliable, lower cost and timely.

2. Through technology transfer of generated basic data, industry can advance the state-of-the-art.

3. Assistance of ecological compatibility with environment (such as fishing grounds, local inhabitants, etc.).

4. Increased personal safety of employees.

1.4 Government Research Role and Needs:

An attempt has been made in the identification of Arctic research needs to determine those areas of investigation most appropriate to 
either industry or government. This section describes the basis upon. which these determinations have been made.

Generally, short- to mid-term research conducted in an atmosphere of relative certainty and low risk should be sponsored by the petroleum industry. The incentive for the private sector to pursue research is greatest when the actual sale of lease tracts becomes imminent and as economic oil and gas discoveries become a reality. Government research involvement should be in those areas where American industry in general and, hence, the ultimate consumer stands to benefit the most. Projects appropriate for government sponsorship include those which offer wide applicability and which tend to be long-term, high-risk, regional, and prohibitively expensive for single companies or small groups of companies. Examples of this are: detailed studies involving measurement and forecasting of ice coriditions; development of an understanding of ice movement and subsequent collision with other ice or with island beaches; failure modes and strengths of ice; and descriptions of sea bottom conditions and soil properties. Government-sponsored research should also include technology transfer which would place overall characterizations and modeling methodology in the hands of industry. This would enhance the private sector's ability to "optimize sutespecific designs with regard to effectiveness, economy, and safety. While the actual design of offshore structures is expected to be performed by industry, research that deals with concepts of testing and instrumentation, scale model experiments, and projects involving computer modeling should be performed with government assistance. 
Industry-sponsored research is usually site-specific. Examples of privately funded investigations are: studies of ice interaction with individual structure types; development of drilling and production systems for these structures; design of support facilities, pipelines,

causeways, enclaves, and terminals; and other logistical systems. It is not expected, for example, that oil companies would conduct seafloor and ice stress studies before lease sales are held.

With the above division of labor between privately and publicly sponsored Arctic research, it is evident that a number of direct benefits result from government-sponsored investigations.

1.5 Arctic Research Needs and Funding:

The participants at the June 30, 1980, Arctic workshop identified 60 major research projects. This recommended program addresses the 12 highest priority items which need extensive research. If research efforts are delayed, the development of Arctic oil and gas resources may likewise be delayed. Current technology restricts the ability to drill and produce in several areas already indentified.

All of the identified projects require basic investigation and/or modelling. Data accumulation and analysis are essential for proper engineering of Arctic oilfield operations. Numerous data bases are severely needed.

Rapid development of Arctic resources depends on the research performed. An eight- to ten-year DOE Arctic research program is needed. The following is a tabulation of the proposed work showing scheduling and costs. 
1.6 Scheduling and Costs (millions of dollars)

\begin{tabular}{|c|c|c|c|c|c|}
\hline & \multicolumn{5}{|c|}{1980 Dollars } \\
\hline & \multicolumn{5}{|c|}{ YEAR } \\
\hline & $\underline{1}$ & $\underline{2}$ & $\underline{3}$. & $\underline{4}$ & $\underline{5}$ \\
\hline Ice Mechanical Properties & 3.5 & 3.5 & 3.5 & 3.5 & 3.5 \\
\hline Ice Geometry & 1.0 & 1.0 & 1.0 & 1.0 & 1.0 \\
\hline Ice Dynamics & .8 & .8 & .8 & & \\
\hline Ice Instrumentation & 1.2 & 1.2 & 1.2 & 1.2 & 1.2 \\
\hline Ice/Structures Interaction & .9 & .9 & .9 & .9 & .9 \\
\hline Ice Forces & 1.0 & 1.0 & 1.0 & .8 & .8 \\
\hline Ice Accretion and Corrosion & .1 & .1 & .1 & & \\
\hline Ice/Structure Instrumentation & 1.0 & 1.0 & 1.0 & 1.0 & .1 .0 \\
\hline Seafloor Gouging & .7 & .7 & .7 & .7 & .3 \\
\hline Soil/Structure Interaction & 1.7 & 1.4 & 1.4 & 1.3 & 1.1 \\
\hline Drilling and Well Completion & .8 & .8 & .8 & .8 & .8 \\
\hline Oceanography & .3 & .3 & .3 & & \\
\hline Tunnelling & .3 & .3 & & & \\
\hline Transportation & $\therefore$ & - & - & - & - \\
\hline Logistics & 2.5 & $\cdot 2.5$ & 2.5 & 2.5 & 2.5 \\
\hline TINATI & $15: 8$ & 15.5 & .15 .2 & 13.7 & 13.1 \\
\hline
\end{tabular}

Total of all projects $=73.3$ million dollars.

\subsection{Priorities (Arctic)}

While all Arctic projects discussed are of vital importance (on critical path of program) to the success of an Arctic program aimed at bringing the necessary technologies on line to accelerate the development of Arctic resources, three priority groupings can be identified: 


\section{Artic Projects by Priority Groups}

\begin{tabular}{|c|c|c|}
\hline Priority & Name & Section \\
\hline & Mechanical Properties & $\overline{1.8 .1 .1}$ \\
\hline Very & Ice Instrumentation & 1.8 .1 .4 \\
\hline High & Ice/structures & 1.8 .2 .1 \\
\hline & Ice/Structure Instrumentation & 1.8 .2 .3 \\
\hline & Logistics & 1.8 .6 \\
\hline & Ice Geometry & 1.8 .1 .2 \\
\hline Medium & Ice Forces & 1.8 .2 .2 \\
\hline High & Soil/Structure Interaction & 1.8 .3 .2 \\
\hline & Drilling and Well Completion & 1.8 .3 .3 \\
\hline & Ucednograpny & \\
\hline & Ice Dynamics & 1.8 .1 .3 \\
\hline High & Ice Accretion and Corrosion & 1.8 .1 \\
\hline
\end{tabular}

In order to recognize the need for Arctic research, it should be pointed out that 47 other work projects were identified at the June 30 , 1980, workshop in Albuquerque, New Mexico. The reader is referred to "Report of the Workshop on. Arctic $0 i l$ and Gas Recovery," dated September 1980 , for further identification.

\subsection{Arctic Research Projects}

Each of the Arctic projects described in detail below is appropriate for government support. All are top priority and on the "critical path." They should be considered as a unified cluster of interlocking and interdependent projects, and represent a carefully refined Arctic program which is oriented towards the ambitious mission of extracting the petroleum resources of Alaska in the most expeditious manner. Some portions of the program. may be executed by other federal agencies, e.g., Department of Transportation and Department of the Interior, but are included in this plan to make it complete and to allow decision-makers to appreciate the interrelationships involved. 


\subsubsection{Ice Characteristics \\ 1.8.1.1 Mechanical Properties}

State-of-the-Art

Before it is possible to design exploration or development structures, or to assess the interactions that might take place between ice and these structures, it is necessary to have an understanding of the mechanical behavior of ice. Earlier research carried out in this area is probably sufficient for today's conservative Arctic operations. However, before more extensive and detailed exploration and production work can be carried out, it will be necessary to obtain more ice property data and to develop an understanding of its applicability to the representative design situations.

Many mechanical property studies concentrate on the linear elastic range. Because the primary concern with ice involves loading to failure, testing should be set up accordingly and rupture criteria established. It is well known that ice mechanical properties are affected by crystal. size and orientation, salinity, temperature, and strain rate. Any material modeling program should be set up to take these effects into accourt.

Much of the ice strength information available today is based on small-scale samples. However, the optimum design of full-scale structures will depend heavily on knowledge of properties on that scale. Additional investigation is needed to understand the size effects on various ice strength parameters.

Past ice properties testing has been carried out by many different organizations using widely varying techniques. In some instances, this 
has led to diverse results and to difficulties in interpretation. At the very least, effort should be directed at the most meaningful and widely accepted methods; perhaps extra emphasis should be placed on accelerating current efforts to standardize procedures and equipment in this area.

\section{Objectives}

1. Most important among the objectives is the obtaining of compressive, tensile, shear and flexural ice strengths. These tests should lead to characterization of the stress/strain relationships, including yield and post-year conditions.

Two additional conditions should be placed on the above objective whenever possible. These are to (1) do the testing in situ, especially on multiyear ridges and ice islands, and (2) carry out smal1- and large-scale tests on the same ice to investigate size effects.

2. Analytical procedures should be developed to predict size effects. Much testing could be eliminated if analytical procedures can be obtained and verified.

3. Obtain friction coefficients for ice-on-ice and ice-on-other materials. To the extent possible, this should be carried out under field conditions. This information is necessary for ride-up/pile-up calculations and for calculating total loads.

4. Obtain adhesion bond strength values for ice and various structural materials. The evaluation of materials or methods for reducing this load source should be included. 
Schedule

It is expected that five years will be needed for completion of this project.

Cost

It is estimated that $\$ 3.5$ million per year will be required.

\subsubsection{Geometry and Structure of Ice Pack and Ridges}

\section{State-of-the-Art}

Owing to their size and strength, pressure ridges and ice islands may be the features governing design for many types of structures. It will be necessary to predict ridge failure modes and resulting forces on structures; therefore, in addition to understanding the mechanical properties of sheet ice, knowledge of the bulk engineering properties of ridges will be required to determine loads.

Some information on ridge sizes and composition is available, but most of these data are for the ridge sail and not for the much larger keel below the water surface. Measurements of many ridge characteristics at various times of the year and at different locations are needed. From these measurements, reasonable parametric bounds for engineering purposes may be determined. From the geometry and bulk composition aspects, it is possible to assess ice/structure interaction problems and select favorable structural configurations. Ice failure modes may be predicted by analysis of ridge composition and consolidation characteristics. Temperature and salinity data will be used to calculate brine volume from which strength indices and other mechanical properties may be estimated. 
It is expected that a good deal of the work required to achieve this project's objectives will require instrumentation development such as a remote seafloor system with upward-looking sonar to obtain ridge keel dimensions and movements. (A dual instrumentation development is described in a separate section.) In addition systematic stereo photography, laser overflights, and sonar measurement programs will have to be conducted to obtain ridge profile distributions.

objectives

Measurements are required of the size, composition, degree of consolidation, temperature, and salinity profiles of annual ice ridges, multiyear ridges, and ice islands.

Schedule

At least five years will be needed for this research.

$\underline{\text { Cost }}$

This study will require $\$ 1.0$ million per year for five years.

\subsubsection{Dynamics}

State-of-the-Art

In addition to about 30 years of historical ice charts, there are. about 10 years of satellite coverage of the Alaskan offshore, The historical ice charts are useful, but the data are spotty, and observations are usually available only during the summer shipping season. There are also large gaps in the satellite data due to limitations imposed by cloud cover and darkness. The resolution of most of this satellite imagery is so coarse that many of the ice features of interest, such as pressure ridges, rubble fields, and multiyear floes, cannot readily be distinguished. Higher resolution data sets (stereo 
photography, laser profilometry, and side-looking airborne radar) are available but currently provide limited coverage in time or space. However, even at best these data sets hardly allow refined estimates of rare events.

Ice-Drift Velocities. Data on ice-drift velocities should continue to be accumulated with added emphasis on coastal areas. Ice dynamic models which emphasize engineering applications should be developed on a regional basis. Satellite and ice-drift buoy data should be compared with any modeling calculations to develop "verified" regional ice dynamics and thermodynamics models for the seas of the Alaskan Arctic. Progress is presently being made in this area. These models should then be run in the hindcast mode using historical barometric pressure fields to reconstruct past records of ice drift. Once verified, these models can be utilized to develop improved estimates of drift velocity.

Location of the Ice Edge. The position of the ice edge can be observed on ESMR and SMMR imagery. Data available from these satellites' microwave system should be analyzed and combined with other satellite data, and with ice reconnaissance data, to provide documentation on ice-edge motions. These data should then be used to test models predicting the locations of the ice edge. Once a model is verified, it will be very useful in forecasting breakouts and ice-edge locations in all of the Arctic offshore.

Objectives

1. All existing and future remote sensing data should be analyzed to obtain ice-drift velocity.

2. Regional ice dynamics models should be developed and verified. 
3. Provide continuous satellite coverage of pack-ice movement.

4. Analyze all remote sensing data to derive statistics of pack-ice edge movement and intrusion events. .

\section{Schedule}

Three years will be required.

\section{$\underline{\text { Cost }}$}

It is estimated that $\$ 750,000$ per year for three years is needed.

\subsubsection{Instrumentation Development}

\section{State-of-the-Art}

The mechanical and physical properties of the many varying types of ice in the Arctic need to be measured, both in situ and in the laboratory. The properties. that are important include in situ stresses, stress-strain relationships, shear strength, tensile strength, compressive strength, fracture toughness, crack distribution, as well as the physical properties of temperature, salinity, density, and consolidation. The correlation of these properties, as determined in situ, with laboratory measurements, needs to be verified. New instrumentation will be required.

Ice ridge properties that are of importance include the bonding and the size of the ice blocks, the salinity of the ice, and the strength profile throughout the ridge.

\section{Objectives}

1. Field and laboratory measuring equipment are needed for ice mechanical-property determinations.

2. An upward-looking sonar capable of simultaneously measuring ice-keel depths and ice-sheet velocity needs to be developed. 
3. An economical ice-stress sensor for in situ application needs to be developed.

Schedule

Five years will be required.

Cost

It will require $\$ 1.2$ million per year for five years.

\subsubsection{Ice Accretion and Corrosion Protection}

State-of-the-Art

Ice accretion from freezing spray can cause an. increase in platform gravity loading and in wave loading. Buildup of frazil ice at the waterline can be much more rapid than spray icing, and in both cases many inches of ice accretion are possible. Designs must accurately assess this additional load, or, alternatively, must include methods for the prevention of ice accretion.

The corrosion protection of steel structures embedded in continuous ice has yet to be accomplished, and special designs may be required which take into account the presence of ice adjacent to the structure.

Objectives

1. To estinate the maximum ice accretion loads to be expected in several regions of the Beaufort, Bering, and Chukchi Seas and develop charts/tables to utilize these data for structure design.

2. To develop methods of accommodating or preventing ice accretion.

3. To investigate the effectiveness of corrosion protection methods with the presence of ice at the structure boundary, and devise suggestions for anode placement in Arctic conditions. 
Schedule

Three years will be required.

$\underline{\text { Cost }}$

Approximately $\$ 120,000$ per year will be required for three years.

\subsubsection{Ice/Structure Interaction}

1.8.2.1 Studies of Ice Behavior Against Structures

State-of-the-Art

Structures that withstand the lateral forces imposed by ice have been used for many years. Artificial gravel islands have been built to withstand the ice regime of the Canadian Beaufort Sea out to the 20-meter water depth. Previous research has included: laboratory testing of ice to better understand ice mechanics; field tests of in situ ice strength; model tests; field measurements around artificial islands; and the development of theoretical models.

Predicting ice interaction phenomena with structures requires an understanding of both ice failure modes and ice mechanics. Given sufficient driving force, ice which moves against a structure will fail locally in the failure mode requiring the least local force. Ice will fail in bending against sloping structures. Ice will fail in either a crushing or buckling mode against vertical structures. Ice which fails initially against a wide structure may not clear away, and subsequent action takes place against the ice rubble in a mixed-mode failure involving both crushing and bending. If ice is frozen to a sloping structure, bending failure cannot take place until the adfreeze bond is broken. Faijure of an ice ridge may be by vertical buckling, by crushing, or by flexural bending in a horizontal plane, depending upon ridge dimensions and properties. 
Our classification of failure modes of ice is fairly well advanced. However, additional quantitative knowledge of the failure modes of a variety of ice features against various types of structures is necessary. For low-freeboard structures with slopes, there is a possibility of ice riding up onto the surface of the structure. Research has already been conducted on this phenomenon, and certain simple models have been developed. It appears that, by utilizing suitable beach geometries and freeboards, rideup onto the working surface of the structure can be avoided (particularly for production structures which will generally have higher freeboards than exploration structures).

Objectives

Program areas which should be considered in evaluating ice/structure interaction are the following:

1. Improve understanding of failure modes of a variety of ice features against various types of structures.

2. Consider test structure verification of ice/structure interaction models.

3. Conduct model tests and carry out field observations to develop predictive theories for ice rideup on islands and structures. Schedule

Eight years will be needed for this project. Cost $\$ 850,000$, per year for eight years will be needed. 


\subsubsection{Ice Forces on Structures}

State-of-the-Art

Knowing the ice forces for particular failure modes enables the total ice force on: a structure to be predicted, if the ice clearing forces can also be predicted. For narrow structures, ice clearing forces can be calculated using kinematic models which are dependent on structure shape, ice piece sizes, and friction. Such models for total forces have been calibrated in both large- and small-scale ice basins and are now considered fairly reliable. However, a test structure would be very desirable to confirm such large-scale ice force predictions.

For very wide structures, which may also be in deeper water and could, therefore, could interact with thick ice features, the total ice force may elimited by the driving force. Typically, the driving force may be controlled by the average ridge-initiation and ridge-building forces acting behind a thick, wide ice feature, such as an ice island. Therefore, for deeper water and large structures, additional knowledge of average ridge-building forces across a wide front is required.

The design of the outer wall of a steel or concrete structure is based on the maximum local ice pressures which can be expected. For ice-breaking vessels, codes for designing for local ice pressures have been established based on experience and testing. However, ships can ram the ice at speeds greater than $5 \mathrm{~m} / \mathrm{sec}$, whereas it is unlikely that stationary structures will be subject to ice velocities greater than about $1 \mathrm{~m} / \mathrm{sec}$. Because of the dependence of ice strength on strain rate, local ice pressures developed for ship design may be conservative 
for structure design. A research program should be undertaken to develop design values for local ice pressures as a function of ice mechanical properties, ice velocity, and contact geometry.

As already discussed, when ice acts against a very wide structure, much of the failed ice cannot clear around the structure; therefore, an ice rubble field is formed. For structures in shallow water or with gradually sloping sides, the rubble may become grounded and become a feature against which the oncoming ice acts. A better understanding of several aspects of ice rubble around structures would assist in the design of offshore structures.

During those seasons when sea ice cover is not complete, there is the possibility of storm-driven ice floes impacting a structure. These impact loads must be evaluated and will certainly be included in structural design load criteria. Such loads are expected to be of greater importance in areas of the Bering Sea, where structures will not be designed for pack-ice conditions as severe as in the Beaufort Sea. Maximum ice floe size during storms, floe motions, and impact loads should be evaluated.

\section{Objectives}

The evaluation of ice forces on structures should be approached by undertaking the following programs:

1. Investigate the influence of random flaws and non-simultaneous structure contact on total ice forces.

2. Develop a model of driving force and average ridge-building force across.a wider structure front.

3. Describe local ice pressure as a function of ice mechanical properties, ice velocity, and contact geometry. 
4. Investigate the characteristics and effects of rubble fields around structures.

5. Evaluate impact loads upon structures from storm-driven ice floes. Schedule

Eight years.

$\underline{\operatorname{Cost}}$

$\$ 1$ million per year for the first three years and $\$ 800,000$ per year for the remaining five years.

\subsubsection{Instrumentation Development}

State-of-the-Art

Reliable instrumentation is critically needed to measure ice. against structure response. Of importance are interactions of sheet ice, ice ridges, and ice islands with gravel islands, production structures, ice-breaking ships, and subsurface pipelines. Instrumentation wi.l involve measurements in the ice itself, on the structure being loaded, and at the interface.

Several other instrumentation systems. may be required. One system, for example, would be an ice-tracking system that is permanently mounted on the seafloor around production structures in deeper water; this would give advance real time warning of thick ice moving toward the structure. and provide opportunities for ice-structure interaction measurements.

\section{Objectives}

1. Develop advanced diagnostic instrumentation, and also inexpensive warning devices, to determine the state of stress in the ice near a structure.

2. Develop a seafloor-mounted, ice-tracking system to give advanced realtime warning of the approach of thick ice features. 
3. Devise instruments to measure ice pressure at interfaces and to determine structure responșe characteristics.

Schedule

Seven years will be required.

$\underline{\operatorname{Cos} t}$

$\$ 1$ million per year for seven years will be required.

\subsubsection{Arctic Seafloor Soils}

\subsubsection{Seafloor Gouging}

\section{State-of-the-Art}

It has been established, from marine geology studies in the Beaufort Sea, that shallow (1 to 2 meters deep) gouges are produced frequently in coastal areas (0- to 15-meters water depth) by the motion of ice ridge keels scouring the seafloor. This relates primarily to the proper burial depth choice in offshore pipeline designs. Burial to 2-meter depth is feasible. However, deeper gouges (2 to 10 meters) occur less frequently, and are less commonly found. They are probably due to multiyear ice ridge keels and ice islands that became grounded. It is important to establish the probability of such a rare event occurring during the projected life of an offshore field operating in a given region so that a pipeline burial depth can be chosen which corresponds to an acceptably low probability of interruption. Three factors relate to these design calculations: (1) ice-gouge dating and recurrence statistics; (2) the mechanics of ice-gouging processes; and (3) the engineering properties of the seafloor sediments. 


\section{Objectives}

1. To verify the accuracy of possible-ice-gouge dating techniques, and to apply the best technique to determine the age of a significant number of ice gouges deeper than two meters.

2. To investigate the mechanics of ice-gouging processes by observing grounded multiyear ice features, the gouge which each has produced, and the specific quantitative boundary conditions in each instance, including ice and gouge dimensions, geotechnical properties of adjacent sediments, and the thickness and physical properties of the surrounding ice sheet which drives against the grounded feature.

3. To test and verify methods for determining the in situ mechanical properties of seafloor sediments in locations subject to deep ice gouges:

4. To analyze age-dating results and observations of actual grounded ice features to produce relationships between icegouge statistics and ice ridge and keel-statistics, and to establish the probability of ice-gouge production in the depth range two to ten meters over the 20- to 1-year time interval of expected offshore operations.

5. To suggest conditions of offshore pipeline burial which relate to the soil strength test results and probabilities established above.

6. Based upon the observations of grounded multiyear ice features, calculate the size and freeboard of artificial islands needed to resist such features, and the size of artificial protective shoals around offshore installations which would successfully stop massive ice features. 
7. To provide tables/charts for use in pipeline design for areas likely to encounter severe gouging.

Schedule

It is estimated that objectives 1,2 , and 3 will require three to four years, and objectives $4,5,6$, and 7 can be completed in one additional year.

\section{Cost}

This program, with three parallel field components, will require $\$ 700,000$ per year for four years, and $\$ 300,000$ in its final year.

\subsubsection{Soil/Structure Interaction}

State-of-the-Art

In the design of any structure, one of the major design considerations to be addressed is that of soil-structure interaction. Before design even begins, a detailed knowledge of soil properties must be known so that proper safety factors can be considered as well as optimum design concepts. By having a working knowledge of these parameters, safe cost-effective structures can be installed.

One major concern at this time is that of frost heave in marine soils and permafrost formation in artificial islands. Increased lateral capacity of gravel islands or gravity structures can be obtained by freezing the near-surface marine sediments. Piles may be considered either alone or with surface-bearing foundation elements for platforms in certain ice-covered waters. Axial and lateral bearing capacities could potentially be enhanced by freezing the soil around these piles.

One aspect of developing an Arctic offshore field would include transporting product to shore through pipeline systems which, in themselves, have special considerations to be addressed. Warm oil seafloor 
pipelines over shallow ice-bonded subsea permafrost may present construction and operational problems. A principal construction problem is the burial of the pipe into frozen permafrost soils. Anchoring a pipe-laying barge on near-surface permafrost may prove difficult in some Arctic locations.

Warm oil flowlines in close proximity to frozen permafrost may be subject to differential settlement and stresses due to thawing and subsidence. The extent of this problem, and possible design solutions, should be studied for offshore areas where near-surface, ice-bonded permafrost is likely to be found.

Another potential problem with pipelines concerns that of chilled pipelines buried in discontinuous permafrost. As a cold line passes through unfrozen fine-grained soils, water will begin to freeze near. the pipe, causing more water to migrate to the face of the frozen material. As the ice mass grows, frost heave takes place causing additional forces to act on the pipe which may lead to failure. Additional studies must be undertaken to develop new burial techniques and other possible design solutions.

Another soil-/structure-related problem area in which additional research is required is that of ground motion from earthquakes. Recent terrestrial observations of structural performance have shown that the ground motions to which a structure responds are different from the ground motions recorded by an instrument in the free field at the same site. The motions to which a structure responds are quite developmentspecific, depending on site conditions and structure characteristics. At present, ground motions at a particular site are estimated by 
referring to measured motion at other similar sites. These ground motions are then input to an analytical process to calculate the forces in the structure. An analytical method should be developed, which is firmly based on physical principles for calculating the effective ground motions for a specific site and structure situation, given the instrumentally recorded ground motions.

Objectives

1. Burial techniques should be developed for pipelines crossing zones of near-surface subsea permafrost.

2. The mechanical properties of frozen soils need to be determined for both marine and terrestial soils.

3. Frost heave mechanịsms, and methods for mitigating frost heave, should be developed.

4. Several seafloor-acceleration measurement systems should be deployed in Arctic offshore locations to determine local motions during earthquakes.

Schedule

Seven years are required.

$\underline{\operatorname{Cos} t}$

Objective (1) $\$ 150,000$ per year for three years.

(2) $\$ 500,000$ per year for seven years.

(3) $\$ 600,000$ per year for seven years.

(4) $\$ 600,000$ for the first year and $\$ 200,000$ per year for years two through four. 


\subsubsection{Soils/Drilling and Well Completion}

State-of-the-Art

Stratigraphy, - origin, and special problems associated with sediments at depth are of importance in the Arctic offshore. Basic information is usually obtained by seismic profiling, deep coring, well logging, and extrapolation from onshore stratigraphic information. Problems in these areas fall into two main categories: subsea permafrost and hydrates.

Thermal history of sediments at depth is one controlling element in the distribution of ice-bonded sediments. Based primarily on drilling experience to date in the Canadian Beaufort Sea, subsea permafrost has been encountered at significant depths. Depending on soil type and salinity, offshore permafrost may be discontinuous with depth. A better understanding of site-specific permafrost conditions will be required for final structural design, well completion design, well-spacing determi-nation, and pipeline design. It is important to know the depth to the upper and lower boundaries of the permafrost as a function of distance from shore and water depth, and to what extent offshore permafrost is discontinuous with depth. To answer these questions, a field instru- mentation and sampling program must be employed. Also, downhole temperature measurements of the permafrost would be very useful .

Although naturally occurring hydrates have not been encountered at Prudhoe Bay, hydrate evidence during drilling has been obtained in the Mackenzie Delta, Arctic. Islands, Canadian Beaufort Sea and west of Pruahoe Bay. Because of potential problems caused by thermal decomposition of hydrates during drlling and production, hydrate intervals 
must be detected and properly cased. Because of the presently inferred impermeability of permafrost, the potential exists for abnormally pressured gas that is trapped within or below permafrost. Such zones. should be recognized and detected as part of any drilling and deep coring program.

If in situ hydrates are present in the Arctic offshore regions, the hydrate intervals will "thaw" or decompose around the wellbore due to heat transfer from warm production fluids. Upon decomposition, the released gas can generate significant pressure on the well casing. Knowledge of maximum pressures is essential for casing design to prevent collapse, unless another approach (pressure relief) is utilized. The pressure buildup due to hydrate decomposition is a function of many variables, including mechanical and strength properties of the hydrate formation.

Cement interaction with in situ hydrates must be understood in order to cement well casing properly within hydrate intervals. Thermaliy generated gas evolved from hydrate sources during placement and setting of cement may permeate the cement slurry, causing a reduction in cement strength and creating permeable paths with loss of a sealing capability. Even in a wellbore drilled with chilled mud, heat of hydration released by the cement as it $\mathrm{se}^{+}$; may cause hydrate gas evolution around the cement sheath.

\section{Objectives}

1. Develop improved cementing systems for application to in situ hydrates.

2. Develop improved drilling techniques for application to in situ hydrates. 
3. Develop a sensing/sampling technique for detecting in situ hydrates.

4. Thaw subsidence for clusters of wellbores penetrating offshore permafrost should be modeled. Thermal properties of subsea permeafrost will be obtained as required.

\section{Schedule}

Five years will be required.

\section{Cost}

$\$ 800,000$ per year for five years will be required.

\subsubsection{Tunnelling to Provide Access to Subterranean Hydrocarbon Production}

State-of-the-Art

Large-diameter tunnels (20 feet or more) have been bored through both competent and incompetent rocks for distances of several miles using both boring machines and blasting methods. These tunnels have been used for many purposes; i.e, water transport, sewage transport, and the transport of people, goods, and materials. Tunnels have been dug under the ocean in many places. Large underground chambers and tunnels now exist in coal mines offshore in eastern Canada and the United Kingdom.

Offshore underground production sites, with access through tunnels, would provide locations for hydrocarbon production uninfluenced by surface environmental conditions such as waves, winds, and ice and would thus open up offshore areas not now available for production. Production and drilling equipment. essentially unmodified from surface land-use would be used. 
The concept of underground tunnels for offshore production is not new. Such techniques have been seriously considered since 1966 or. before. Studies that have been made, however, were more or less piecemeal paper studies; there has been no concentrated attempt to. consolidate these studies and reach an acceptable final conclusion on the viability of the tunnelling concept and the range of conditions under which this concept would be both applicable and efficient.

\section{Objectives}

The objective of this project is to provide information that will allow reasonably valid decisions to be reached on the feasibility and applicability of tunnelling to offshore Arctic operations. Reaching this objective will require review of past work on underground production systems, review of the safety aspects of underground operations, and some projection of tunnelling rates and costs. Safety considerations must be given maximum consideration to assure that the dangers of producing $0 i 1$ and gas in underground caverns can be overcome.

\section{Schedule}

It is estimated that the review process and projection of future tunnelling capabilities would require about two years.

\section{$\underline{\text { Cost }}$}

Estimated cost is $\$ 500,000$.

Government Role

Most of the work on this project would be done by tunnelling consultants. The government's role will be to select consultants, supervise the work, and publish results. 


\subsubsection{Arctic Oceanography}

1.8.4.1 Ice Cover Effects on Wave Generation and Maximum Waves Expected State-of-the-Art

Several very specific aspects of the Bering Sea oceanographic regime have a significant impact upon the engineering design of offshore struc- tures. In particular, the presence of ice cover for part of the year in shallow regions (20-meter depth), such as Norton Sound, is expected to influence surge and storm tide heights, as well as reduce wave genera- tion. The maximum wave height in such shallow regions during storms is governed by nonlinear effects, and only linear theory is commonly avail-able. Furthermore, in the summer, open-water season in deeper water, the prediction of the maximum wave height to be expected within a 100- year recurrence interval has been done using only simplified theory, and some experts believe that the present value (131 feet) is an overly conservative one.

\section{Objectives}

1. Verify hindcast models for the Bering sea that include the influence of ice cover wave and surge generation, and shallow water effects.

2. Produce a refined and detailed estimate of the maximum wave height expected, with a 100-year recurrence interval, for the Bering and Chukchi Seas.

3. Determine the wave heights expected during extreme storm conditions and fractional ice cover, to provide information for calculations of ice floe impact loads against. structures. 
Schedule

It is expected that three years will be required for the simultaneous completion of objectives 1,2 , and 3 . This project could be a part of the Department of the Interior's Outer Continental Shelf (OCS) Environmental Assessment Program.

\section{Costs}

A projected cost of $\$ 300,000$ per year for three years is appropriate.

\subsubsection{Arctic Transport}

\subsubsection{Icebreaking Vessels}

State-of-the-Art

Icebreaking ships will be required in the Arctic to transport oil and gas (tankers), to provide logistical support (supply/work boats), to support construction (dredges, pipelayers), and to control ice buildup in transit lanes and around offshore loading terminals (icebreakers). This will require ice-breaking vessels of varying capability, depending upon the region. Although existing ship design techniques could be used, significant improvements in efficiency are expected from research into such topics as propulsion efficiency, propeller integrity, hull structural integrity, maneuverability, and ship/terminal interaction: of particular importance is the concept of a marine transport and supply system which operates ycar-round in the ice-infested waters of the Bering and Chukchi Seas.

\section{Objectives}

1. To improve the capability of ice-breaking vessels to penetrate multiyear ridges and pressured ice fields. 
2. To improve icebreaker profiles and propeller designs.

3. To model and verify techniques for ship maneuvering and ship/ terminal interactions in ice.

4. To initiate vehicle development for shallow ice-covered water.

5. To design an advanced ice surveillance system to be used in an operational mode for ship routing in ice-infested waters.

Schedule

An 8-year interval is expected for this set of objectives.

$\underline{\operatorname{Cos} t}$

No costs are given since this part of the Arctic program is expected to be defined more precisely by the U.S. Coast Guard and the Maritime Administration.

\subsubsection{Logistics}

State-of-the-Art

Access to field locations during the winter, several hundred miles from civilization with research teams and equipment, requires a separate budget for logistics. Experience has shown this to be more expensive each year as air charter and fuel costs escalate.

nhjertive

Provide access to research sites in the remote Arctic offshore regions.

Schedule

Annually for eight years.

Cost

$\$ 2.5$ million per year for five years; $\$ 1$ million per year for years six, seven, and eight. 


\subsection{OFFSHORE RESEARCH}

DOE has had a small effort in offshore research since June 1975 to address instrumentation problems previously not performed by industry. This small program has produced some excellent benefits, mostly in seafloor instrumentation, but it should be expanded. Some examples are:

1. High data rate acoustic telemetry-Method for transmitting measured data from seafloor instrumentation through the water to the surface.

2. Seafloor Earthquake Measurement System (SEMS) - An instrument which is implanted on the seafloor which measures and records the response of seafloor soils to strong earthquakes.'

3. Geotechnically Instrumented Seafloor Probe (GISP) - An instrument which measures pore pressure in underconsolidated sediments. When lowered to the seafloor, its probe penetrates the sediments, measures the pore pressure, records the data, and transmits it on demand.

4. Marine Sediment Penetrometer - An instrument which can be dropped from ships or: aircraft that embeds in the seafloor and measures soil shear strength.

\subsection{Objective:}

The main objective of the offshore research is commensurate with the previously stated overall goal of the proposed AODT program and is, specifically, to accelerate development of domestic $0 i 1$ and gas production from offshore resources. The means of reaching the objective is through implementation of the research program described herein. 
The project activities are achievable and will provide basic engineering data for both industry and government. The lack of such information has restricted the rate of offshore development. Without a significant effort in this proposed offshore research, the lack of knowledge and engineering data, plus limited deep water technology, will continue to act 1 ike a brake -- holding back offshore developments.

2.2 Introduction:

This proposed offshore research program can assist industry in providing near-term relief of domestic energy deficiencies. The program can influence the rate of development of offshore oil and gas resources.

It is evident that oil and natural gas will continue to be the dominant components of the U.S. energy mix for the remainder of this century. Informed estimates indicate that from 50 to 60 percent of our total domestic energy supply will be provided by oil and gas in the year 1990. Offshore $0 i 1$ and gas production provides a significant portion of our current domestic production. Currently 13 percent of our domestic $0 i 1$ and 26 percent of our domestic gas are produced from the OCS.

OCS oil and gas production will, become even more important in the future. Industry estimates that the OCS will eventually provide 60 to 70 percent of all new petroleum discoveries. In addition, one-half of a11 domestic production must come from presently undiscovered resources by 1990 if oil production is to be maintained at 8.6 million barrels per day or increased.

Assessing such information regarding the U.S. energy situation, it is clearly evident that: 
1. $0 i 1$ and gas will remain the major energy source for the remainder. of this century.

2. The OCS currently provides substantial amounts of $0 i 1$ and gas.

3. The OCS offers one of this nation's best possibilities for new discoveries.

Therefore, there is a critical need to accelerate the development of this nation's OCS petroleum resources to fully utilize the enormous production potential of our own resources.

\subsection{Impacts:}

The benefits which the United States, will derive from the recommended Offshore Technology program are that more $0 i 1$ and gas will - be provided to the consuming public sooner with reduced environmental risk and significant national economic benefit.

1. More oil and gas will be provided because the ocs is the most likely place to find new reserves.

2. The oil and gas will be provided sooner because the data and technology required by both government and industry will be developed faster.

3. The petroleum resources of the OCS will be developed with reduced environmental risk because a better definition and understanding of natural forces and hazards will provide the basis for the safest possible development.

4. National economic benefit will be realized through increased lease and royalty income, reduced production costs, and reduced deperidence on imports. 


\subsection{Government Role in Offshore Research:}

The federal government controls the pace of OCS development by virtue of its congressionally mandated leasing and regulatory responsibilities.

The development of OCS resources is, therefore, a shared responsibility between the federal government and private industry. The federal government is responsible for leasing federal lands and regulating OCS resource development. Industry has been, and should continue to be, responsible for the exploration, production, and transportation of the resources. The acceleration of OCS petroleum resource development will require, a. cooperative effort between government and industry.

Government responsibilities in the OCS are fragmented and scatterec through several departments and agencies: DOE, BLM, USGS, Army Corps of Engineers, U.S. Navy, EPA, USCG, and NOAA. Among these agencies witr specific OCS programs, there-are numerous areas where responsibilities rema in unclear because of program overlap or gaps in program coverage. A program which focuses and coordinates these diverse, fragmentec efforts toward the single goal of accelerated OCS oit and gas development is needed.

DOE's leadership of this program is dictated by both its mission and its capabilities. The legislated mission of DOE is to provide an adequate and reliable energy supply and to coordinate all government energy research and development. DOE has the demonstrated capability to initiate and manage large, multidisciplined research and technology programs. Because of its nonregulatory role in the OCS, DOE can organize 
the cooperative programs between government and industry which will be required to achieve the goal of accelerated OCS oil and gas development.

The proposed program does not terminate the involvement of the various government agencies presently involved in OCS activities. The role of the DOE will be to coordinate, focus, and support those efforts to assure the realization of the overall objective of accelerated ocs development.

2.5 Offshore Research and Development Needs

The DOE workshop, in January 1981, identified two principal areas of OCS research and development which should be starting points for the DOE Offshore Technology Program.

1. The collection of engineering data which characterizes the ocs environment (meteorological, oceanographic, and geology) and the hazards that environment poses to petroleum development.

2. Research and technology development for resource recovery in very deep water.

These are both major activities with numerous projects as discussed below.

Need for Engineering Data Base

A good meteorological and oceanographic data base is necessary in order to assess extremes and operational values of water column motions (waves and currents). Available sources for such data are: marine/ navigation reports, data collected from rigs, data collected from weather ships, data collected from instrumented buoys, and information obtained from fixed offshore installations. At best these data bases permit varying degrees of extrapolation/interpolation, but they do give 
some insight into recurrence intervals and discreet values such as wave heights/periods and current velocity. Unfortunately, the extensive data base which does exist for United States OCS waters resides in the files/ data banks of various governmental and industrial bodies, and is not accessible in a correlated and readily usable manner. Techniques for reducing data have not been standardized, and the formats for presenting the reduced data varies. There is a need to define not only the quality and precision of the data but also for development of industry-wide standards for analyzing and presenting the reduced information.

Development of offshore. petroleum resources is governed by the schedule of leasing and the implementation of plans for production. Both phases depend on knowledge of environmental and geologic conditions within an acceptable range which will allow the government to offer lease tracts for sale in a timely fashion, and which will assure the installation of safe structures for the development of the resources. Seafloor engineering is an integral part of the decisions affecting leasing (e.g., whether stipulations will be attached to given tracts) and development (e.g., the type of structures designed for the tract).

Leasing is presently expanding from the relatively shallow waters of the Continental Shelf to deep water areas (Continental slope and Rise). The nature of geologic conditions and processes on the Slope and Rise are just beginning to be recognized. However, the schedule of accelerated leasing requires that information in quantitative engineering interpre-pretation of the existing processes be available much earlier than in prior years for the Continental Shelf, where the background knowledge already had a broader base. For instance, the 
understanding of submarine'slope stability will be a key factor in moving resource development into the deep water OCS areas. In another example, the presence of gas hydrates below the Slope was only recently discovered; whether hydrates will be treated as a resource, or more likely as a hazard, is yet to be determined.

The critical problem in addressing most seafloor engineering (geotechnical) problems is the absence of key, specialized, and reliable (long-life) instrumentation to measure fundamental soil properties, such as shear strength, pore pressure, permeability, porosity, consolidation coefficient, gas content, etc. In addition; the response. characteristics of the seafloor sediments to external forces--such as earthquakes, storm waves, and sea ice--must be understood for the design and operation of offshore structures.

Deficiencies in present day technology exist in sampling techniques,. in situ (both near-surface and downhole) measurements, extended field observations, and in laboratory-based testing procedures. These deficiencies become even more acute with increasing water depth. A list of problem areas is presented in the Department of Commerce publication, "Present and Recommended U.S. Government Research in Seafloor Engineer- ing" (1978).

Advancing Deep Water Technology

Deep water drilling and producing technology covers the materials, procedures, and techniques for conducting drilling; well completion, and production operations in deeper waters than are now accessible through existing methods. 
Wells have been drilled from platforms in a maximum water depth of 1,025 feet, and from drill ships using a deep water circulating riser at maximum water depths of 4,876 feet. The state-of-the-art of deep water drilling technologies is considerably ahead of deep water completion and production technology. Hydrocarbons are being produced from maximum water depths of 1,025 feet using production platforms; however, production using existing techniques and equipment for seafioor completions has been accomplished only to depths of about 500 feet. Emphasis must be placed on advancing the technology for deeper water completions and production.

\subsection{Definition of Proposed Program}

The recommended program consists of two principal program elements: 1. OCS Engineering Environmental Data Base.

2. Advanced Technology Development for Deep Water.

The oCS Engineering Environmental Data Base element is better defined at this time because of ongoing programs within DOE and other agencies .

The first year" activities must be directed to three specific work areas:

1. The establishment of working relationships among the various government agencies involved and between government and private industry.

2. The comprehensive planning of the total program effort.

3. The continuation of ongoing technology development projects which clearly meet the needs of the recommended program. 
There are existing data banks and data collection programs ongoing within the federal government. The agencies conducting these programs must be made a part of the recommended program so that their expertise can be applied to the DOE goal of accelerated OCS development. An interagency steering committee will be established to develop and implement working agreements among the involved agencies (DOE, DOI; and DOC). A government/industry advisory group consisting of representatives of the involved federal agencies and technical experts from the private sector will be formed to assure that the program is responsive to the needs of all potential data users.

-A comprehensive, detailed plan of the total program effort must be formulated. The program planning effort will:

1. Appraise the existing data sources as to availability and probable adequacy for DOE's objectives.

2. Develop a consistent and precise definition of the data need of each of the OCS frontier areas.

3. Define the action and resources required to acquire the needed data in a time frame consistent with DOI's lease schedule.

4. Identify research and technology development necessary to develop new tools and techniques.

5. Define the correlation, analysis, and modeling techniques required to accomplish hindcasting and forecasting.

6. Define the organization and operation of the data base. 
Ongoing research projects developing new tools and techniques for collecting heretofore unavailable data will be continued. These projects, initiated jointly by DOE and the Department of the Interior (DOI) (U.S. Geological Survey) and with the support of private industry, focus on the in situ measurement of key parameters affecting the behavior of the seafloor (geological environment) and the response of the seafloor to external forces such as earthquakes. Significant technological advances have been made by this project in the areas of underwater data communi-cation and instrumentation.

The second year's activities will focus on the execution of the detailed plan. The data base will be established, appropriate existing data will be put into the data bank, needed data collection programs will be initiated, and research on new tools and techniques will continue.

The duration of the recommended engineering environmental data base program is tied directly to the DOI leasing schedule and should continue until the U.S. OCS leasing program is complete.

It is anticipated that private industry will share the cost of data collection in subsequent years. However, it should be assumed that the federal government must pay for the first two years until the effectiveness of the program is demonstrated.

The precise definition of future funding requirements will be a result of the detailed program plan.

The Technology Development for Deep Water element is not as well defined as the data base element because the development of offshore technology has been an evolutionary process. Onshore technology was 
extended to shallow water, and from there the technology has proceeded, step by step, to the water depths curreritly being worked. The transition from production in 1,000 to 2,000 feet of water to production in 4,000 feet or greater will require massive technological innovation. The petroleum industry states that production technology generally lags exploratory drilling capability by seven years. The recommended DOE program will shorten that time period by focusing its resources on farreaching, basic research in disciplines which directly affect deep water production technology. Two specific examples of areas which are appropriate for inclusion in this program element are: (1) support of the National Science Foundation (NSF) Ocean Margins Drilling Program (OMDP), and (2) basic materials research focusing on the development of lightweight materials for use in structures and risers.

The first year's activities within this element will concentrate on:

1. Support of and participation in the NSF OMDP.

2. Comprehensive needs evaluation and research program planning.

The NSF OMDP will address and solve many of these problems as they drill and sample the sea floor to a depth of 20.000 feet in 13,000 feet of water. The experience gained in the course of the OMDP will be directly related to deep water oil and gas exploration. Therefore, support of, and participation.in, the OMDP is a fundamental part of the recommended DOE program. Subject to coordination with NSF, it is recommended that $\$ 3$ million be budgeted for DOE support of OMDP.

During the comprehensive planning of the total deep-water technology element, a general assessment of the state-of-the-art in deep 
water production technology and the identification of the basic research needs will be accomplished. Research needs will be prioritized, and a comprehensive program plan will be developed.

\subsection{Scheduling and Costs}

The following is a listing of identified work areas showing scheduling and costs. The listing is by priorities selected at the workshop. These work areas fall within the program identified above. 
OFFSHORE RESEARCH PROJECTS

Estimated Scheduling and Costs

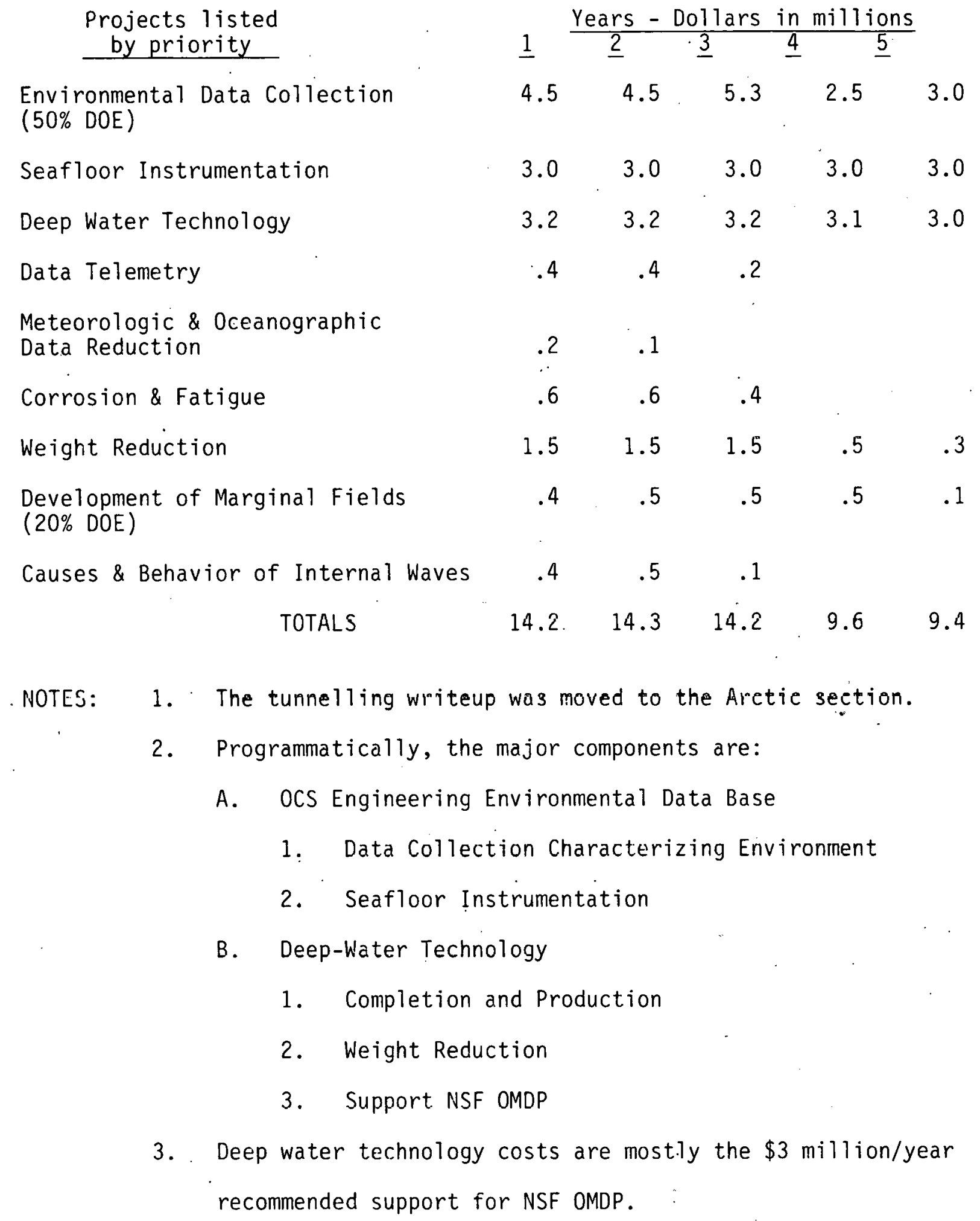




\subsection{Priorities}

The offshore committee discussed the identified projects and ranked them by priority as shown below.

\section{OFFSHORE PROJECTS LISTED BY PRIORITIES}

Government Participation Advisable

\section{PROJECT}

Environmental Data Collection

Seafloor Instrumentation

Deep Water Technology

Datá Telemetry

Meteorologic \& Oceanographic Data Reduction

Corrosion \& Fatigue

Weight Reduction.

Development of Marginal Fields

Causes \& Behavior of Internal Waves

$$
\frac{\text { POINTS }}{(\operatorname{Max}=50)}
$$

50

50

46

46

45

28

24

19

18
PRIORITIES

(Top $=1)$
1

2

2

3

5

6

7

8

Note: The Offshore Group writeups covered only those projects in which a government role by DOE was desirable. The writeup on tunnelling was moved to the Arctic Section. 


\subsection{Offshore Research Projects}

\subsubsection{Environmental Data Collection}

State-of-the-Art

A data base is necessary in order to assess extremes and operational values of water column motions (waves and currents). Available sources for such data reside in marine/navigation reports; data collected from rigs; data collected from weather ships; data collected from instrumented buoys; and from fixed offshore installations. At best these data bases permit varying degrees of extrapolation/interpolation, but do give some insight into recurrence intervals and discreet values such as wave heights/periods and current velocity. Unfortunately, the extensive data base which does exist for U.S. OCS waters resides in the files/data banks of various governmental and industrial bodies, and is not accessible in a correlated and readily usable manner and is not usually engineering oriented.

\section{Objectives}

There should be a multiplicity of objectives to improve the "water column" data base to a status of "common departure" for the offshore industry. Each user could then assimilate and apply these data as their technological ability and philosophy dictate, but the commonality of a starting point would steer the final results to being more comparable and should enable more intelligent and earlier assessment of OCS lease environmental constraints. This, in.turn, should facilitate planned development and greatly assist in assessment of operational economics -all. in turn contributing to accelerated availability of ocs reserves. The multiple objectives of this program are: 
1. Correlation of existing data from government, industry, and academia .

2. Assimilation of the appropriate satellite program imagery into the data collection system.

3. Installation of data collection buoys at strategic locations.

4. Improvement/extension of hindcast modeling techniques to extend the data base; modeling to be calibrated by feedback from the three previous items.

5. The ultimate objective of the above items would be a reliable data base, for any U.S. OCS area of interest, which would be a definitive basis for development of a leasing plan, facility design, economic life assessment, and operational constraint identification. These data would be available from a common source for all and, as mentioned earlier, could be used by each as technology dictated.

Schedule

The schedule should be in segments, some possibly overlapping, just as the objectives are segmented.

Item (1): This should take a concerted effort of five men for a period of three years $=15$ man-years.

Item (2): This should also be 15 man-years over a three-year period but could be made parallel to item 1 .

Item (3): This could be a continuing effort over many years; but for the purpose of this exercise should be considered as a five-year effort, in parallel with (1) and (2), and would involve cost components of man-years, hardware, marine equipment, and instrumentation. 
Item (4): This effort is estimated at 15 man-years over a threeyear period beginning in the third year so as to have some feedback from the first three items.

Item (5): This item would begin at end of the fourth year as a five-man-year per year effort and run indefinitely.

\begin{tabular}{|c|c|c|c|c|c|}
\hline \multirow[b]{2}{*}{ Item 1} & \multicolumn{2}{|c|}{ Millions } & $\begin{array}{l}\text { of } 1980 \\
\text { Year }\end{array}$ & \multicolumn{2}{|c|}{ Dollars } \\
\hline & 1 & 2 & 3 & 4 & 5 \\
\hline $\begin{array}{l}\text { Manpower } \\
\text { Expenses } \\
\text { Computer } \\
\text { Subtotal }\end{array}$ & $\begin{array}{l}0.5 \\
0.2 \\
0.3 \\
1.0\end{array}$ & $\begin{array}{l}0.5 \\
0.2 \\
0.3 \\
1.0\end{array}$ & $\begin{array}{l}0.5 \\
0.2 \\
0.3 \\
1.0\end{array}$ & $\begin{array}{l}- \\
- \\
-\end{array}$ & $\begin{array}{l}- \\
- \\
-\end{array}$ \\
\hline \multicolumn{6}{|l|}{ Item 2} \\
\hline $\begin{array}{l}\text { Manpower } \\
\text { Expenses } \\
\text { Computer } \\
\text { Subtotal }\end{array}$ & $\begin{array}{l}0.5 \\
0.2 \\
0.3 \\
1.0\end{array}$ & $\begin{array}{l}0.5 \\
0.2 \\
0.3 \\
1.0\end{array}$ & $\begin{array}{l}0.5 \\
0.2 \\
0.3 \\
1.0\end{array}$ & $\begin{array}{l}- \\
- \\
-\end{array}$ & $\begin{array}{l}- \\
- \\
- \\
-\end{array}$ \\
\hline \multicolumn{6}{|l|}{ I tem 3} \\
\hline $\begin{array}{l}\text { Manpower } \\
\text { Expenses } \\
\text { Equipment (hardware) } \\
\text { Marine Equipment } \\
\text { Instrumentation } \\
\text { Subtotal }\end{array}$ & $\begin{array}{l}1.0 \\
0.4 \\
2.0 \\
3.0 \\
0.6 \\
7.0\end{array}$ & $\begin{array}{l}1.0 \\
0.4 \\
2.0 \\
3.0 \\
0.6 \\
7.0\end{array}$ & $\begin{array}{l}1.0 \\
0.4 \\
2.0 \\
3.0 \\
0.6 \\
7.0\end{array}$ & $\begin{array}{l}1.0 \\
0.4 \\
- \\
1.6 \\
0.5 \\
3.5\end{array}$ & $\begin{array}{l}1.0 \\
0.4 \\
- \\
1.6 \\
0.5 \\
3.5\end{array}$ \\
\hline \multicolumn{6}{|l|}{ Item 4} \\
\hline $\begin{array}{l}\text { Manpower } \\
\text { Expenses } \\
\text { Computer } \\
\text { Subtotal }\end{array}$ & $\begin{array}{l}- \\
- \\
-\end{array}$ & $\begin{array}{l}- \\
- \\
-\end{array}$ & $\begin{array}{l}0.5 \\
0.2 \\
0.8 \\
1.5\end{array}$ & $\begin{array}{l}0.5 \\
0.2 \\
0.8 \\
1.5\end{array}$ & $\begin{array}{l}0.5 \\
0.2 \\
0.8 \\
1.5\end{array}$ \\
\hline \multicolumn{6}{|l|}{ Item 5} \\
\hline $\begin{array}{l}\text { Manpower } \\
\text { Expenses } \\
\text { Computer } \\
\text {. Subtotal }\end{array}$ & $\begin{array}{l}- \\
- \\
-\end{array}$ & $\begin{array}{l}- \\
- \\
-\end{array}$ & $\begin{array}{l}- \\
- \\
-\end{array}$ & $\begin{array}{l}- \\
- \\
-\end{array}$ & $\begin{array}{l}0.5 \\
0.2 \\
0.3 \\
1.0\end{array}$ \\
\hline $\begin{array}{l}\text { Totals/Year } \\
\text { DOE/Year }\end{array}$ & $\begin{array}{l}9.0 \\
4.5\end{array}$ & $\begin{array}{l}9.0 \\
4.5\end{array}$ & $\begin{array}{l}10.5 \\
5.25\end{array}$ & $\begin{array}{l}5: 0 \\
2.5\end{array}$ & $\begin{array}{l}6.0 \\
3.0\end{array}$ \\
\hline
\end{tabular}


Government Role

Inasmuch as the government has purview over all OCS areas, is a repository for much "water column" data, and manages/finances the satellite programs, they are--by necessity--a member of the suggested program. Also, they are the natural designee for a "neutral" repository and monitor of this information, available to the petroleum industry in particular and the public in general. It is envisioned that they (DOE) would coordinate all of the suggested programs with the work being done by academia, consultants, or by government agencies (e.g., item 5).

DOE and USGS are now jointly supporting an environmental data collection and compiling system; therefore, it is envisioned that this joint operation would be expanded and would probably include the Navy, the Marine Board, NOAA, et al.

\subsubsection{Meteorological and Oceanographic Data Reduction}

State-of-the-Art

Meteorological and oceanographic data are collected for several purposes, but the data collected for one application may not suffice for another. In the offshore industries, environmental data are needed for designing structures and in planning and conducting offshore operations. In the case of design, maximum wave heights, wind speeds, and current velocities are needed for long recurrence periods (normally 100 years), and wave spectra must also be considered. For operational purposes, daily meteorological information is needed as well as extended forecasts, seasonal variations, lengths and severity of storms, etc.

Techniques for reducing data have not been standardized, and the format for presenting the reduced data varies. There is a need to 
define the quality and precision of the data and to develop industry-wide standards for analyzing and presenting the reduced information.

\section{Objective}

Provide guidance and establish a framework to standardize environmental data analysis, reduction, and reporting format. This is needed to assure a uniform data base.

\section{Schedule}

This information is needed today. It should require two years or less to complete this project. Using a steering committee of recognized offshore experts will save time and assure a usable product. The following steps should be taken:

1. A series of workshops with a steering committee to develop a project plan.

2. Conduct sensitivity. analysis and comparative studies to establish preferred analytical techniques.

3. Prepare and have industry critique reporting format.

4. Preparation and distribution of final report.

$\underline{\operatorname{Cos} t}$

It is estimated that $\$ 200,000$ will be required in the first year and $\$ 100,000$ in the second year.

Government Role

Provide the focal point and cover cost of developing standard techniques. 


\subsubsection{Sea Floor Instrumentation}

\section{State-of-the-Art}

Development of the offshore petroleum resources is governed by the schedule of leasing and the implementation of plans for production. Both phases depend on knowledge about the range of environmental and geologic conditions at a level acceptable to offer lease tracts for sale in a timely fashion, and to install safe structures for the development of the resources. Seafloor engineering is an integral part of the decisions affecting leasing (e.g., whether stipulations need to be attached to given tracts) and development (e.g., the type of structures - designed for the tract).

Leasing is presently expanding from the relatively shallow waters of the OCS to deep water areas (Outer Continental Slope and Rise). The nature of geologic conditions and processes on the Slope and Rise are just beginning to be recognized. However, the accelerated leasing schedule required that quantitative engineering interpretation of the existing processes be available much earlier than for prior lease sales where the background knowledge already existed. For instance, the - understanding of submarine slope stability will be a key factor in moving resource development into the deep water OCS areas. In another example, the presence of gas hydrates below the Slope was only recently discovered. (Whether hydrates can be treated as a resource, or more likely a hazard, is yet to be determined.)

The critical problem in addressing most seafloor engineering (geotechnical) problems is the absence of key, specialized, and reliable (long-life) instrumentation to measure fundamental soil properties, such 
as shear strength, pore pressure, permeability, porosity, consolidation coefficient, gas content, etc. In addition, the response characteristics of the seafloor sediments to external forces, such as earthquakes, storm waves, sea ice, must be understood for the design, operation, and survi-val of offshore structures.

Deficiencies in present day technology exists in sampling techniques, in in situ (both near-surface and downhole) measurements, in extended field observations, and in laboratory-based testing procedures. These deficiencies become even more acute with increasing water depth. A list of problem areas is discussed in detail in the Department of Commerce publication: "Present and Recommended U.S. Government Research in Seafloor Engineering" (1978).

\section{Objective}

To develop and demonstrate effective operation of instrumentation systems to determine the fundamental engineering properties of submarine soils and the response characteristics of these soils to external forces.

\section{Scope}

Elements of this project are:

1. Analytical studies to understand the range and variations in basic geotechnical processes as input to defining key soil parameters and providing a guide to develop the needed instruments.

2. Instrumentation development; design; fabrication and testing of devices and sensors (piezometers, pressure core barrels, P\&S probe, etc.) for such key parameters as pore pressure, shear strength, gas bubble physics, etc.; and for response measurements of the mechanics and failure potential of soils (e.g., in earthquakes). 
3. Improved laboratory testing facilities and procedures, especially for analyses of pressurized core samples and for cyclic testing of soils.

4. Extended field observations for the testing of instruments and for the collection of data, with emphasis on operation in hostile areas and extending the data base in frontier regions.

5. Complementary research involving electronics, battery technology, acoustic telemetry, etc:

Schedule

Continuation of current research, coupled with new initiatives and with the need for long-term measurements, designates this as a ten-year program.

Initial effort consists of continuation of testing and improvement of instrumentation system currently under development; the seafloor earthquake measurement system; technically instrumented seafloor probe; acoustic telemetry and penetrometer technology; and the startup of research into wireline sensors for deep water, dynamic pore pressure changes, and pressure core barrel technology.

$\underline{\text { Cost }}$

Estimated at $\$ 3,000,000$ per year.

Government Role

This technology is required to speed the development of the OCS. The DOI is neither staffed nor funded to develop the required instrumentation. The USGS can offer the scientific and engineering expertise in the use of instruments for the collection of data and the interpretation of results. In addition, a strong interaction with the private 
sector, both the major petroleum companies and the geotechnical consulting industry, is needed to assure that DOE's program is responsive to the needs of both government and industry. The USGS and DOE have jointly funded previous projects to the satisfaction of both; i.e., seafloor instrumentation by Sandia.

\subsubsection{Materials}

\subsubsection{Weight Reduction}

State-of-the-Art

The current state-of-the-art in offshore development in the United States is to construct platforms made of steel. These platforms utilize normal construction-grade steels with yield stresses in the range of 36 to $50 \mathrm{ksi}$.

As the development of oil and gas resources has moved to deeper waters, the cost of the template-type structure has grown at such a rate that the development of some known reservoirs is economically unattractive. To counter this the oil industry has developed designs which use buoyancy forces to support all or part of drilling and production structure weight, e.g., guyed towers, tension_leg platforms, and buoyant risers. These new types of compliant platforms could utilize lighter materials that do not impose any degradation of material properties or imposition of severe cost constraints -- either as initial costs or maintenance costs.

This problem of weight is also affecting riser technology. As risers increase in length, larger stresses are imposed on both the platforms supporting them and on the risers themselves. 


\section{Objective}

The project objective is to speed the development and/or utilization' of lighter materials which can be effectively used in the offshore industries. These materials could be steel, other metallic alloys, nonmetallic, or composites. In conjunction with this development, new connection techniques may need to be developed which are more suitable to these lighter materials than currently used welding practices. It may also require utilization of fabricated shapes that are not currently utilized.

\section{Schedule}

This is a long-term project. It should begin as a literature search to identify the materials available, the effects of the marine environ- ment on these materials, and material properties. It should then con- tinue through the improvement of certain material properties and connectors, and the development of more suitable fabricated shapes. A comparison of the new materials to materials currently used will be required along with an information transfer program. This requires periodic review of new developments in materials and recurring cycling through the process.

1 The government has supported studies on the use of composite materials in air frames. Engineering know-how needs to be disseminated so other industries may utilize these materials. 


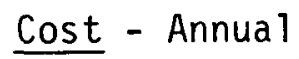

Project Manager

$\$ 40,000$

Staff - Engineering

60,000

Staff - Secretarial

20,000

Personnel

$\$ 120,000$

Computer Costs

$\$ 60,000$

Reproduction

20,000

Seminars

40,000

Project Contributory Costs

$1,200,000$

Total (Annual)

$\$ 1,440,000 \cong \$ 1,500,000$

Government Role

The government role should be to coordinate and encourage, through partial funding, development of new materials and to present this information to the engineering community through publications and forums (seminars). This will have the effect of increasing the availability of $0 i 1$ and gas resources.

\subsubsection{Corrosion and Fatigue}

Sta.te-of-the-Art

Offshorc structural materials problems involve the structure (platform), the riser, and subsea equipment and piping. (For this discussion, only U.S. waters are considered; Arctic and driliing problems are excluded.) Special materials problems include corrosion and fatigue. Corrosion may be the single biggest materials problem, in terms of general design and maintenance considerations. Fatigue, however, can cause cracks that can lead to failure of members and joints and, even in the extreme case, to catastrophic, complete failure of the structure. 
Inspection and monitoring to assess the effects of corrosion and identify significant cracks are difficult in practice. Underwater conditions and normal marine growth on underwater components (which generally must be removed for inspection) make regular inspection difficult. Repair of damaged components may be impossible for extreme corrosion and, hence, may require replacement of members. When fatigue cracks are detected, repairs will be difficult and expensive.

The marine environment causes corrosion in the splash zone and above water, and cyclic loading leads to possible fatigue. For the main plat-form in deep water, the cyclic loading is in the range of the natural frequency of the platform. Cyclic loading comes from normal wave action and/or normal operations; i.e., cyclic loading is typical of the opera- tions. Under operating conditions, significant stress-enhanced corrosion and stress cracking, including thermally activated processes, can occur on a microscale and lead to severe fatigue crack formation.

Data on materials properties and their relationship to corrosion were developed either through accelerated laboratory corrosion tests or have resulted from experience on actual structures. The laboratory data are the most. numerous and have been obtained under controlled conditions but tend to be under accelerated test conditions; that is, 10-to-30-year life data cannot be obtained practically via laboratory testing for 10 to 30 years. Therefore, the laboratory tests are at high cyclic rates to speed up the tests. Fatigue data currently available were obtained under single-level stress conditions and fixed-cycle rates. Further investigation of the effect of high fluid pressure and marine environment is desirable. Uata on nonmetals are more complicated than 
for metals, and much less information is available. Obtaining such data on nonmetals is generally much more difficult than for metals.

\section{Objective}

The objective of this task shall be to develop an understanding of corrosion and fatigue response of selected materials used in offshore environments. The emphasis shall be on metals first, and then on nonmetallic materials (e.g., concrete and fiberglass) and composites (e.g., concrete-steel sandwich structures). Environments of intèrest, seaair, multiaxial stress conditions, and underwater pressure shall be considered.

\section{Schedule}

Task 1. Tests and analysis shall be conducted to understand corrosion of selected metals under sea-air and underwater marine conditions. Emphasis shall be placed on accelerated type tests, whereby corrosion data can be obtained within short time periods. Coatings for metals shall be considered, with emphasis on practical application to offshore components.

Task 2. Fatigue tests and analysis shall be made on selected metals of interest. Sea-air and underwater marine environments (fatigue under high fluid pressure) shall be considered. Multilevel stress conditions shall be considered.

Task 3. Fatigue of selected nonmetal, structural materials shall be considered. Both homogeneous and nonhomogeneous (1ike reinforced concrete and concrete-steel sandwich structures) shall be considered. 


\section{$\underline{\operatorname{Cos} t}$}

An estimated cost of five to eight man-years of effort and about $\$ 200,000$ per y̆ear for materials and equipment are estimated for a period of three years.

\section{Government Role}

This program should be supported. by government funds, as the results are of general interest and useful to many groups. Additionaliy, the costs for this research are too great for any one group to support.

The government role should be to emphasize coordination of information and development of understanding, and to communicate such to the engineering community through publications, seminars, and the like.

This work effort will be evaluated thoroughly before any investigations are performed because the industry labs work on this problem continuously. The seminars, with publication of the technical papers, would be an inexpensive way to disseminate information.

\subsubsection{Deep-Water Technology}

State-of -the-Art

Deep water drilling and producing technology covers the materials, procedures, and techniques for conducting drilling, well completion, and production operations in deeper waters than are now accessible through existing methods.

Deep Water Drilling. Wells have been drilled from platforms in a maximum water depth of 1,025 feet, and from drill ships using a deep water circulating riser at maximum water depths of 4,876 feet. The state-of-the-art of deep water drilling technologies is considerably ahead of deep water completion and production lechnulogy. 
Deep Water Production. Hydrocarbons are being produced from maximum water depths of 1,025 feet using production platforms; however, produc- tion using the existing techniques and equipment for seafloor comple- tions has been accomplished only to depths of approximately 500 feet. Emphasis must be placed on advancing the technology for deeper water completions and production.

\section{Objectives}

1. To provide maximum emphasis on resolving the best technology for the uccessful completion and production of $0 i 1$ and gas wells in water up to 6,000 feet in depth.

2. Lesser emphasis is to be placed on drilling technology for drilling in deep water because this technology is well under way.

3. Participate in and support the deep water OMDP of the NSF.

\section{Concepts}

The greatest need is that of developing one or more technologies for completion and production of oil and gas wells at water depths up to 6,000 feet. One approach to the well completion problem, advanced by members of industry, suggests that technology be developed to complete deep water production wells at. the ton of a produrtinn riser equipped with a diver working-level located at a point of about 500 feet subsea, which is below the turbulent water resulting from storms. It is believed by some that this concept can be developed by utilizing one or more buoys at the top of the riser at a fixed location. Once this is accomplished, the upper part of the riser could be disconnected and pulled back to the drill ship. At a later date the submerged working level and riser top could be relocated, equipped with production 
equipment, and flow lines connected to become a buoyed subsea completion.

Finding a solution to this problem should receive much emphasis. Of course, other approaches to this problem should be evaluated.

Action Required

1. Members of industry and/or DOE should undertake research studies as follows:

-- Determine the feasibility of various proposals for completing oil and gas wells at water depths up to 6,000 feet, with special consideration of the above described concept.

-- Finalize the technology, plans, and demonstration for drilling oil and gas wells in offshore waters up to 6000 feet in depth.

- Participate in technology developments and cooperate in funding deep water OMDP of the. NSF.

Cost

Rough estimate is $\$ 225,000$. for study only; support NSF is $\$ 3$ million per year.

Government Role

-- Specialized supporting research.

-- Coordinate supplemental research on deep water completions.

-- Participate in all meetings of the NSF deep water OMDP Project Committee and provide technical and financial support.

\subsubsection{Supporting Research}

2.9.6:1 Causes and Behavior of Internal Waves

State-of-the-Art

Internal waves (high amplitude, long wave length waves beneath the sea surface) exist in several parts of the world (Andaman Sea, East 
Coast of United States, Mediterranean Sea, etc.). These waves generate high currents which are damaging to drilling and production equipment unless warning is provided or the equipment is protected. The causes of such waves and their behavior are partially, but not completely, understood. Better understanding of these waves would lead to improved drilling and production operations. Much work has been done by NOAA, but the results have not been conclusive.

\section{Objective}

The objective of this project is to develop enough understanding of internal waves to allow prediction of their occurrence and the magnitude of the forces that they may generate on equipment in their path. To reach this objective will require development of the physics of these waves, mathematical modeling of the waves based on these physics, and observational verification of the results. A first step may be a comprehensive study of NOAA data.

Schedule

Estimated timing of this project is two years.

$\underline{\text { Cost }}$

Estimated cost is $\$ 1,000,000$.

Government Role

This project would be best conducted by a major university. The government's role would be to finance the project and monitor and distribute the results.

\subsubsection{Marginal Field Technology}

State-of-the-Art

Because of the high cost. of installing offshore production systems, many marginal hydrocarbon discoveries are not developed because of the 
prohibitive costs necessary to instail production/transportation systems and provide a reasonable payout.

\section{Objective}

Develop technology that will permit the economic limit of marginal fields to be improved by a factor of at least. 1.25 .

\section{Schedule}

Five years.

\section{First Year}

1. Investigate areas which, with improved technology, are most likely to provide a beneficial solution to the objective.

2. Investigate other industries for existing technology which may be applicable to the problem.

Second - Fourth Year

Develop and test those methods proposed.

Fifth Year

Evaluate methods and run field demonstration tests.

$\underline{\operatorname{Cos} t}$

$\$ 10,000,000$ total; DOE cost-sharing 20 percent -- $\$ 2,000,000$.:

Government Role

Cost-sharing role. Estimate industry at 80 percent and DOE at 20 percent.

\subsubsection{Data Telemetry Projects.}

2.9.6.3.1 Data Telemetry - Offshore Platform to Onshore Office

State-of-the-Art

Data telemetry is presently utilized in specific areas using the allotted radio-phone frequency bands to a microwave system. The systems 
used are not real time and are generally used for the transmission of only the most important data.

Objective

Develop a reliable data telemetry system capable of operating in a hostile environment and transmitting data in real time, so that a home office evaluation of logging data could be made simultaneously with an on-site evaluation. Long-range transmission capabilities could be necessary because this instrumentation would most likely be used on remote or offshore applications.

Schedule

Two years.

$\underline{\text { Cost }}$

$\$ 500,000$.

Government Role

National Laboratories (Sandia and Los Alamos) and contractors are presently working on telemetry and communication systesm. Future work is contingent on results and priorities. The committee considered this as a low priority role.

\subsection{Data Telemetry - Platform to Ocean Floor}

State-of-the-Art

At the present time data telemetry techniques are utilized in some applications, particularly on drill ships and semi-submersible rigs. The present systems are multiplex, electrohydraulic, and hydraulic. These systems are not as reliable as desired, as suddenly moving off location (storm or failure of positioning system) will cause a loss of contact with seafloor equipment and a loss of ability to close the blowout preventers. 


\section{Objective}

Design a reliable deep water system (probably acoustically controlled) that would be dependable and in contact with ocean bottom control, even when the rig is off location, as well as to keep the dynamically positioned drilling vessel on location.

Schedule

One year from start up.

$\underline{\operatorname{Cost}}$

$\$ 200,000$ to $\$ 500,000$.

Government Role

Several National Laboratories (Sandia and Los Alamos) are working in the field of telemetry and would be well qualified to work with the petroleum industry in this project.

\subsection{Downhole Telemetry (Logging While Drilling)}

\section{State-of-the-Art}

Attempts have been made to log while drilling since the early 1930's. A sometimes workable instrument was offered to the petroleum industry in the early 1950's, utilizing a mud pulse technique for transmission of a simple electrical curve.

Recently DOE/BETC has funded development of an instrument using the mud pulse technique that has overcome some of the shortcomings of the 1950 instrumentation.

\section{Qbjective}

Develop a reliable, long-lived logging-while-drilling instrument that would not in any way interfere with drilling operations. Such an instrument should ultimately be capable of transmitting all types of 
logging data to the surface, resistivity, S.P., acoustic, nuclear, and orientation data (for directional drilling control). This would probably only be used on deep expensive wells, most of which are located offshore.

This project may be out of context. It is being worked on in the drilling industry. No doubt it would be used extensively offshore.

Schedule

One year.

Cost.

.. $\$ 200,000$ additional.

Government Role

National laboratories and government contractors are presently working on telemetry projects. The drilling group addressed this subject and recommended no new starts since many companies in the private sector are working on telemetry systems. 


\subsection{DRILLING RESEARCH}

\subsection{Program Objective:}

The program objective is to accelerate development of domestic oil and gas resources through drilling research. The objective can be reached by addressing two action modes:

1. Advancing the state-of-the-art of current technology.

2. Developing advanced drilling systems.

\subsection{Background:}

Development of all petroleum resources is dependent on the use of drilling technology. The amount of drilling limits the number of new discoveries and new production. Recognizing this limiting barrier, a small but effective drilling research program has been employed since June 1975. Several significant technology advancements have been achieved (both basic knowledge and commercialization) even with a meager budget. For example:

1. The DOE/Sandia Improved Pressure Coring System now being extensively used in reservoirs is being considered for enhanced oil recovery.

2. Applying the diffusion bonding technique to polycrystalline diamond compact. bits .

3. Optimization of deep drilling parameters in a laboratory simulated deep drilling environment.

4. The Advanced Electrodril System now nearing operational status.

5. The now commercially available. Teleco mud pulse telemetry system for directional drilling. 
Drilling research can have a near-term energy impact on increasing oil and gas production by providing more drilled footage per year. The drilling research budget needs to be increased by a significant amount to implement a maximum effective program.

\subsection{Introduction:}

A true understanding of the need to increase the national drilling capability occurs only when the following information is studied. Essentially all the nation's drilling rig fleet has been drilling at capacity since 1974, yet imports increased from 40 to 50 percent by 1979. It is evident that more annual drilled footage is essential if domestic production rates are to be significantly increased above the normal decline rates. The only exception to this statement is if wells pro- ducing higher volumes were discovered or higher production rates were obtained from already existing wells. Since oilfield suppliers, equip- ment, and rig-building facilities have also been operating at near capacity, it is apparent that the steady increase in annual drilled footage since 1974 cannot be accelerated except by external forces. The economic incentive through "high" $0.1 \mathrm{l}$ prices and price decontrol has already allowed significant profits. Currently, the demand for drilling of in-fill wells, enhanced oil recovery wells and low permeability, low volume gas wells can only be met with a sacrifice on exploratory and development drilling. Some methods to increase the annual drilled footage capacity are as follows:

1. Increase activity in drilling research that will provide increased penetration rates, reduce nonrotating time, and provide basic 
research for drilling associated problems. Note: these actions have the effect of increasing the footage capacity of existing drilling rigs.

2. Increase or develop additional rig-building capacity.

3. Induce U.S.-owned rigs which are drilling in foreign countries to be returned for domestic drilling.

- Work toward item Nos. 2. and 3 are now being performed, but very little effort is exhibited toward No. 1 -- drilling research.

Implementation of a significant drilling research plan can provide early results. The program needs to stay in effect until the annual drilled footage capacity is increased from the current 300 to 550 million feet per year. That extra amount of drilling may provide for about a 6-million-barrel per day increase in oil production above the current 8.5 MMBD, assuming current reserve finding rates of 21 barrels per foot drilled persist in the future. This computes to a 5.3-billion-barrel oil-equivalent per year increase. Without drilling research, the 550 million feet per year can only be reached when about 5500 drilling rigs are working.

Now, consider the possible effect of drilling research!! If a major technology development (such as a high-speed drill bit, a jet erosion drill system, or a modular add-on Electrodril system) could double the wells per rig, the needed footage could be reached in one to two years with the existing rigs. Adding substantial drilling research activities will shorten the time needed to achieve the desired drilling capacity. 


\subsection{Impact:}

This proposed program can have a significant impact on the nation's economy and energy self-sufficiency, providing an effectively focused effort is made to solve the identified problems. First, the total energy resource base cannot be developed because of limitations in our ability to cope with hostile surface or downhole environments such as sloughing shales, great depths, high temperatures, high pressures, and sometimes poisonous conditions. Cost reductions will have a direct pass-through in terms of increased reserves and increased producing rates. Each year most companies allocate a more or less fixed portion of their expected revenue to drilling wells; they will drill as many feet of hole as these funds will cover. Statistically, each foot of hole will find a given amount of oil and gas (mentioned above) which will support a given pro- ducing rate. Consequently, the reduction in drilling cost will be directly reflected in increased reserves and producing rates.

\subsection{Drilling Research Needs:}

The drilling research needs were identified at the workshop. The drilling group identified 34 projects and six advanced drilling systems which should be investigated. These were then screened for a desired government role, and it was recommended that 17 projects and five advanced systems needed government research. It was decided that the remainder was the responsibility of private industry alone. The prioritized project list with estimated costs is presented herein.

Several identified data base requirements have been needed for many years but are clearly outside the realm of individual private sector companies. Examples are: 
1. Post well drilling data analylsis for general correlation.

2. Downhole/real time data collection and analysis.

3. Pore pressure and fracture gradient data.

4. Developing alternatives to strategic materials.

The first three items concern information that is always needed before drilling a well, especially exploratory wells. All of the needed information will not be available in any one company's records. The need is emphasized when considering that 75 percent of the wildcat wells are drilled by independent operators with limited engineering data and professional personnel.

The fourth item is clearly a need for government research. Some strategic materials such as cobalt, chromium, and tungsten orginate from politically unstable areas of the world. Hence, cost and availability are a constant threat toward oilfield material shortages. A supply interruption, due to military action, etc., could seriously impact the operation of the petroleum industry.

Some needs concerning advanced drilling systems were identified as the sole responsibility of government research. Some examples are: (1) horizontal drilling system, and (2) advanced directional drilling system.

Both of these systems are necessary for developing the unconventional energy source "methane gas in coal seams." There is no economic incentive for development by private industry. The risk is too great. Unless government research funds are made available to perform this drilling research, "methane drainage" will be delayed as an energy source. The potential return, however, is great because these systems will also be applicable for heavy oils, tar sands, and oil shale. 


\subsection{Research Role of the Drilling Industry}

In order to understand the role, the reader must first recognize that the drilling industry is not Exxon, Shell, Amoco, Gulf, Texaco, Conoco, etc. They are production companies. The drilling industry is Loffland Bros., Parker, Penrod, Signal, Delta, Dual, Moran, etc., and 80 percent of the land drilling rigs in the United States are owned by companies with five or fewer rigs. The producing companies, the service companies, and the drilling contractors make up the petroleum industry. Only when the reader understands the above, can he understand the reason for the limited amount of advanced drilling research that is performed. A good analogy might be the seafood manufacturers who probably do very little research on shrimp boats.

The petroleum industry performs extensive research in the areas of reservoir and production engineering but very little research in drilling. The industry's highly segmented approach to drilling is undoubtedly responsible for this. Basically, the oil company controlling the well supplies the capital, a drilling plan, and general supervision for drilling the well. A drilling contractor supplies the basic rig, manpower, and operating supervision. A large number of other separate companies furnish services and supplies such as the drilling mud, solids control equipment, drill bits, special drill string components, bore hole surveying and directional control devices and service, logging, and a myriad of other necessary materials and services. The research per-formed has been by a very few of the large integrated oil companies and major service companies. The drilling contractors, the people actually drilling the wells, have generally 
lacked the capital resources needed to conduct research and have relied on empiricism from field operations to improve their operating capabilities. Although there has been a great deal of improvement developed in this manner, operations still remain rather primitive. There is a real need for a total systems approach to drilling. This has been recognized and several firms have initiated efforts along this line.

The suppliers have done varying amounts of research on items like logging, drilling fluids, bits, and cementing; but the majority of other products were merely manufactured instead of being optimally designed. Although many of the critical needs are well recognized, generally there has not been sufficient profit incentive to the suppliers, due to low sales potential, to justify the risk and expense of significant research.

The beginning effort in the total systems approach, while surely in the right direction, will be little and too slow in developing to meet the immediate needs of the nation to develop our $0 i 1$ and gas resources. Therefore, there is a need for additional research in many areas, some of which do not fit into industry research programs, because they are high- risk, long-term or basic in nature.

3.7 Government Role in Drilling Research

Prior to the OPEC oil embargo of 1973-74, essentially all conventional drilling research was performed by the petroleum industry. This work was performed mostly by major oil producers and suppliers and resulted mostly in product improvement. Government drilling work was 
limited to unique projects, such as big-hole drilling at the Nevada nuclear weapons test site. At the time of the embargo, oil imports were 40 percent of U.S. demand; thus it became apparent that, considering domestic production decline, the petroleum industry needed to drill more domestic wells if imports were to be reduced. Prices and profits were low, thereby impeding domestic development. Only 1400 rigs were operating in the United States. The big profits were overseas. This environment precipitated a 1975 National Research. Council ad hoc meeting on drilling capability which recognized a significant need for additional drilling research. Thereafter, the Drilling and Offshore Program started in June 1975 with FY 76 budget of $\$ 5$ million.

In an effort to influence the reduction of oil imports, the federal role has been to draw expertise from industry's research centers and national labs to advance the state-of-the-art through research applications. Government-supported research can provide expertise not always present in the oil industry, e.g., General Electric development of the Electrodril. An additional advantage of government-supported research is its widespread availability, i.e., all results are published.

The energy demands for the near future will require more crude oil and natural gas. Successful drilling research will provide methods to reduce drilling costs by increasing penetration rates and advancing the state-of-the-art. Such action will stimulate more drilling and exploration and, thereby, increase the nation's petroleum production and recoverable reserves. Drilling research by industry will continue to take place but it needs to be accelerated. 


\subsection{Drilling Research Program and Funding}

In order to fulfill the objective of accelerating domestic oil and gas production, the following program elements are identified. A prioritized list of identified projects follows below. The program elements are:

1. Advancing state-of-the-art for conventional technology,

2. Developing advanced drilling systems,

3. Safety research, and

4. Environmental research.

An advisory council with industry, academia, and government expel tise should be formed to guide the program. Annual meetings evaluatina progress and goals will ensure effective results.

The 5 -yeartotal is $\$ 47.8$ million. An FY 83 budget of $\$ 7.4$ million is needed to fully implement the total program. However, considering budget limitations, a cost of $\$ 5.2$ million would be needed to begin performing the 13 highest priority projects.

\subsubsection{Scheduling and Costs}

The estimated time required to perform each project with the estimated cost is presented in the following tabulation. The detail information is reported under each subject in the drilling project section. 
Drilling Research Projects

Estimated Scheduling and Costs.

Projects listed by priority

Earth Stress

Borehole Stability

Post-well Drilling Data Analysis

Alternatives to Strategic Materials

High Temperature Elastomers

Advanced Directional Drilling System

Rock Properties from Logs

Surveying Accuracy

Jet Cutting

Fluid Dynamics

Downhole/Real Time Data Collection and Analysis

Horizontal Drilling

Cementing High Angle Holes

System Integration Analys is

Pore Pressure and Fracture Gradient Data Analysis

Rock Cutting Phenomena

Improved Seals

Drill String Analysis

Automatic Drill Pipe Inspection

Coal Seam Sensor

Sensor Concepts

Electrodril

Magnetic Anomaly Data

Totals $\frac{\text { Years }-1980 \text { Dollars in Millions }}{1}-\frac{2}{3}-4 \quad 5$

$.3 \quad .5 \quad .5$

$\begin{array}{llllll}.2 & . & 3 & .3 & .3 & .3\end{array}$

$\begin{array}{lllll}.8 & 1.0 & 1.0 & 1.0 & 1.0\end{array}$

$\begin{array}{lllll}.5 & .6 & .6 & .5 & .4\end{array}$

$\begin{array}{llll}.2 & .2 & .3 & .2\end{array}$

$\begin{array}{lllll}.7 & 2.2 & 5.0 & 5.0 & 5.0\end{array}$

$\begin{array}{lllll}.4 & .6 & .6 & .5 & .4\end{array}$

$\begin{array}{llll}.6 & .8 & .6 & .2\end{array}$

$\begin{array}{lll}.3 & .4 & .1\end{array}$

$.2 \quad .3$

$\begin{array}{lllll}.5 & .6 & .6 & .5 & .1\end{array}$

$.2 \quad .4 \quad .4$

$\begin{array}{lll}.3 & .5 & .1\end{array}$

$.2 \quad .1$

$\begin{array}{lllll}.6 & .6 & .8 & .6 & .1\end{array}$

$\begin{array}{lll}.2 & .3 & .3\end{array}$

$.1 \quad .1$

.1

$\begin{array}{lll}.2 & .3 & .3\end{array}$

$.3 \quad .2$

$\begin{array}{llll}.1 & .6 & 1.0 \quad .5\end{array}$

.2

$\begin{array}{llllll}-.2 & -3 & -.2 & - & -\end{array}$ 


\subsubsection{Priorities}

The workshop participants separated the identified research projects into two groups: government role and nongovernment role. These pro- jects were then priorotized. The two prioritized lists are presented below.

\section{DRILLING PROJECTS LISTED BY PRIORITIES Government Participation Advisable}

\section{PROJECT}

Earth Stress

Borehole Stability

Post-weil Drilling Data Analysis for General Correlations

Alternatives to Strategic Materials Used

in Drilling for Petroleum or Other Energy Resources

High Temperature Elastomers

Advanced Directional Drilling System

Rock Properties From Logs

Surveying Accuracy

Jet Cutting Drilling

Fluid Dynamics

Downhole/Real Time Data Collection \& Analysis

Horizontal Drilling

Cementing High Angle Holes

System Integration Analysis

Pore Pressure \& Fracture Gradient Data Analysis

Rock Cutting Phenomena

Improved Seals

Drill String Analysis

Automatic Drill. Pipe Inspection

Coal Seam Sensor

Sensor Concepts

Electrodril

Magnetic Anomaly Data

\section{POINTS \\ $\underline{(\operatorname{Max} 60)}$}

60

60

59

56

54

53

51

51

50

49

49

49

49

46

46

45

42

40

40

38

35

28

14
2

PRIORITIES

$($ Top $=1)$

1

1

3

4

5

6

6

7

8

8

8

8

9

9

10

11

12

12

13

14

15

16 


\section{PROJECT}

Non-Clay Fluids

Cuttings Cleaning ( 0 il Mud)

Corrosion Related Materials Problems

Solids Control

High Performance Lubricants for Downhole Tools

Deep Fluid Motor

Downhole MWD/Logging

Directional Drilling Systems

Cuttings Transport

Improved Bits

Fluid Abrasion

$0 . i 1 /$ water Separation

Drill Pipe Coatings

Production Damage

Wellbore/Cement/Casing/Design

$\mathrm{H}_{2} \mathrm{~S}$ Detection

Alternate Cutting Materials

Flexible Drill String Drill

$$
\text { POINTS }
$$$$
\underline{(\operatorname{Max} 60)}
$$

48

47

47

45

44

43

43

42

42

32

28

26

17

17

16

12

9

0
PRIORITIES $($ Top $=1)$

These projects, in which the workshop participants foresaw no government role, are separated in this report (see Section 3.10, page 123). They were studied in the workshop, and recommendations for the necessary scope of work were made. 


\subsection{Drilling Research Projects with a Government Role}

\subsubsection{Conventional Technology}

\subsubsection{Rock Mechanics}

An understanding of the stresses and deformations of rocks before, during, and after driliting is required for evaluating borehole stability, for reliable casing program development, and for the design of improved drill bits. Significant progress has been made in rock mechanics in recent years, but increased oil and gas production in more hostile environments necessitates the development and demonstration of better rock mechanics capabilities. In addition, detailed evaluations of selected phenomena associated with drilling are required for many of the formations and techniques planned for use in unconventional resource recovery. The three high-priority areas of rock mechanics research which have been identified are described below.

\subsection{Earth Stress.}

Knowledge of the in situ stress is critical in assessing the stability of an open borehole. It is also necessary for the design of a casing program that will ensure the integrity of the well during its anticipated 1 ife.

\section{State-of-the-Art}

Current estimates of the in situ stress state rely primarily upon the interpretation of hydraulic fracturing data. Suggested improvements include wireline systems for measurements during small hydrofractures and techniques for measuring stress relief during borehole movement. Current in situ stress models are generally isostatic and do not account for realistic phenomena important to accurate predictions. Models for 
predicting in situ stresses need improvement to incorporate in a more realistic manner the layering effects of geologic strata and nonelastic response of the material to overburden and tectonic forces.

\section{Objectives}

The objective of this program element is to evaluate and improve techniques for measuring, interpreting and relating rock properties and in situ. stress so that the factors affecting wellbore mechanical stability are understood and optimal design of drilling and casing programs can be achieved. A secondary objective will be to catalog currently available data on in situ rock mechanical properties and earth stress from major oil and gas producing basins. The major tasks in this research effort are as follows:

Develop and Validate a Model to Predict Earth Stresses. numerical model of the structure of a particular basin should be developed. The model should then be correlated with data gathered in the next tasks to demonstrate that the model is useful for accurately predicting in situ stress that will be experienced during drilling and completing wells in the basin. The methodology for extending the isostatic models to other regions should be thoroughly detailed and the prediction model made available for industrial use.

In Situ Stress Data Collection From Major Producing Basins. The results of all available in situ stress measurements made to date in major producing basins. should be catalogued for use in casing program design and for use in model validation. Consideration should be given to the measurement technique used, and emphasis should be placed upon a thorough evaluation of data from basins in which abnormal stress conditions have previously resulted in extensive casing damage. 
Techniques/Instrumentation for In Situ Stress Measurement. A laboratory and field test program is required for evaluating the downhole stress measurement techniques currently employed. Improvements in these systems should be sought and evaluated in field and laboratory model scale tests.

\section{Schedule}

A two-phase effort is required in this endeavor. In phase 1, the initial model development, data collection, and instrumentation evaluation will be completed. Specific recommendations for phase 2 activities will be made regarding the additional data required (if available) to complete the data base. In addition, techniques for measuring in situ stress will be evaluated in detail, and recommendations for pursuing development of new techniques will be made, if appropriate. Similarly, additional requirements for model development and validation details will be presented. Phase 2 activities will then commence if phase 1 results indicate a reasonable potential for payoff. Phase 1 to cover one year; phase 2 to cover two years.

\section{$\underline{\text { Cost }}$}

Phase 1 at $\$ 300,000$ per year and phase 2 at $\$ 500,000$ per year. Government Role

The high technology associated with the development of improved modeling, instrumentation and interpretation techniques, and the broad applicability of the results of the data cataloging efforts provide impetus for this work to be done under government direction. 


\subsection{Borehole Stability}

Renewed emphasis must be placed upon the evaluation of borehole stability as a result of the use of high-angle directional holes, production from deeper wells, and in situ processing of coal, oil shale, and tar sands. Stability evaluations will include not only the open hole but also an assessment of the response of the casing during completion and production activities.

State-of-the-Art

Currently available techniques for evaluating borehole stability must be extended or modified as the environment becomes more hostile. For example, hole collapse associated with plastic flow is critical in predicting the response of a horizontal borehole in heavy oil formation during in situ processing. Fluid/rock interaction must be studied more closely to evaluate the effects of various drilling fluids on stability of the host rock during drilling, particularly in shale formations. Similarly, the production of oil and gas from deeper and hotter formations requires extension of techniques to evaluate more accurately the effects of higher in situ stresses, both tectonic and thermal generated, in the casirig during cementing and production.

\section{Objective}

The objective of this program element is to develop and demonstrate improved techniques for evaluating the stability of cased and open holes. The renewed efforts in this area should be divided into two task areas. The first task will be to assess the stability of open boreholes, including the effects of hole inclination, and to assess constitutive models developed for simulating the response of media such 
as shale, tar sands, coal, and/or others. Fluid/rock interaction effects will also be simulated and measured in the laboratory on a large number of samples of the various strata being drilled in the major producing geo- logical basins throughout the United States. The second task will include the evaluation of the stability (integrity) of cased holes during cementing and production activities. In situ stresses, cement properties (both mechanical and thermal), and casing sizes are critical inputs for assessing the stability of cased holes.

\section{Schedule}

A long-term, relatively low-level of effort program is envisioned in this area. Initial emphasis on high-angle holes and unconventional resource recovery should yield fruitful results.

$\underline{\operatorname{Cost}}$

First year-- $\$ 150,000$; second, third, and fourth years- $\$ 250,000$; and fifth year-- $\$ 300,000$.

\section{Government Role}

The government role in this research project should be in the development and demonstration of the technology for evaluation of the stability of boreholes drilled in hostile environments. Transfer of this technology to industry will allow their use of the proven techniques for evaluating specific problems inherent to resource recovery.

\subsection{Rock Cutting Phenomena}

Investigations of the mechanics of the cutting/drilling process are required to aid in the design of advanced drill bits. These studies 
should concentrate upon understanding fundamental concepts of rock fracture during cutting to allow increases in the cutting rates and bit life in the downhole environment.

\section{State-of-the-Art}

Previous investigations of cutting phenomena have generally concentrated upon average tool forces and have not considered the mechanics of rock fracture. Similarly, the analytical models used to simulate the fracture process must be formulated. Significant advancements in drilling efficiency can be anticipated if the research is extended to include both analytical and experimental simulation of the rock/cutter interaction with increased emphasis upon how the rock is being fractured.

\section{Objective}

The objective of rock cutting research activities is to develop rock fracture data and valid simulation capabilities to allow optimal design of mechanical cutters for drilling under downhole conditions. Major tasks in this area include the following experimental and analytical investigations:

1. Develop and demonstrate analytical simulation capabilities for describing the cutting process in various rock types under downholc conditions.

2. Perform cutter experiments to evaluate tool forces and temperatures, and evaluate rock fracture mechanisms.

The results of this research will then be used in prototype bit design to allow validation or evaluation of the simulation results in field applications. This work should also form the basis for the development of cutting heads for advanced drilling systems. 
Schedule

A 3-year program with a possible extension into advanced drillins systems is currently needed.

$\underline{\cos t}$

First year-- $\$ 200,000$; second and third years-- $\$ 300,000$.

Government Role

The high technology research in rock/cutter interaction is appropriate for government research.

\subsubsection{Fluid Systems}

\subsection{Fluid Dynamics}

\section{State-of-the-Art}

One of the principal unresolved problems in increasing penetration rate is proper definition of the influence that fluid flow through the bit has on both bit tooth cleaning and removal of debris from between the bit and the rock being drilled. A basic understanding of theoretical fluid dynamics would be fundamental in understanding and resolving this problem. Some random experimental work has been done on this topic, but, without a better understanding of the physics of the process, an optimal solution is doubtful.

\section{Objectives}

The objective of this project is to reduce drilling costs by increasing penetration rate by developing a fundamental understanding of the role of fluid dynamics in cleaning the bit and removing the cuttings from underneath the bit that prevent deep penetration of the bit teeth into virgin rock. A theoretical study of the energy requirements and energy dissipation of a jet penetrating the particle-laden fluid beneath 
the bit is required. This would include determining the proper distribution of energy between tooth cleaning and cuttings removal. An understanding of fluid dynamics would assist in improving the design of steel-toothed, insert, diamond, and PDC-type bits.

A second objective is to develop equations that more accurately predict the relationship between drilling rate and numerous drilling parameters.

Schedule

A two-year program is proposed. The first year would be a theoretical and experimental study of the physical phenomena; the second year would be actual driliting experiments using improved design, jet nozzles, and jet nozzle placement on the face of the bit.

$\underline{\text { Cost }}$

First year-- $\$ 200,000$; second year $--\$ 300,000$.

Government Role

Most of the needed work and information is basic research and has industry-wide application. Active government participation was recommended by the workshop committee. Industry will no doubt continue with Edisonian research at a rather low rate, but government assistance is needed to accelerate a theoretical understanding of basic fluid dynamics.

\subsubsection{Drilling Systems Anatyses}

Considerable information presently exists throughout the oil and gas drilling industry concerning conventional drilling. Various collections of data (discussed below) can be used to improve the general knowledge about conditions affecting drilling. It is considered that the government (DOE) can be a control manager to collect and analyze the 
data for the general benefit of the overall oil and gas drilling industry. Various individual companies have attempted such projects in the past. However, even though such data-gathering within their own companies has been beneficial, the data contained within an individual company are insufficient to make the complete analysis.

Because of the competitive nature of the industry, collection of data by one company from other companies cannot be accomplished. Thus, this is the motivating force for government involvement in this type of activity.

The following projects have been identified as appropriate for government to sponsor:

1. Pore pressure and fracture gradient regional data collection and mapping.

2. Post-well drilling data analyses.

3. Surveying and data gathering of magnetic anomalies to improve directional well control.

4. Production damage: (a) while drilling, (b) during completion, and (c) during production.

Additionally, two more topics were identified as research areas for drilling systems analyses. These are:

1. Drill string analyses.

2. Systems integration analysis.

\section{Schedule}

The schedule to accomplish the above projects is presented below in the discussion of the individual projects. The time needed to accomplish this entire program depends upon whether or not the projects are under- taken concurrently. 


\section{$\underline{\text { Cost }}$}

The approximate cost to accomplish all tasks will be $\$ 7.0$ million. However, several of the projects contain ongoing monitoring of data and updating the results. Thus, deperiding upon the intensity of effort and timing of those projects, the costs may vary significantly.

Government Role

The government role for each of these projects is discussed below.

\subsection{Pore Pressure and Fracture Gradient Data Analyses}

State-of-the-Art

Considerable costs and risks are experienced by the $0 i 1$ and gas industry because of the threat of a blowout. Many advances have been made in the areas of predetermining, from drilling data and wireline logs, the pore pressures and fracture gradients of the formations being penetrated. However, because the formation pressures and fracture pressures exist on regional bases, considerable monetary savings (arid safety for both men and equipment) can be realized by having a reasonable knowledge of these pressures during the well planning stages. In particular, this knowledge would lead to properly planned casing setting depths and casing designs. In addition, drilling fluid programs can be planned which would enhance the overall drilling project.

\section{Objective}

The overall project objective would be to convert data gathered from operators into maps containing pore pressures and fracture gradients. These would be publicly available for use in well planning.

\section{Schedule}

If the government could and would undertake such a project, from the time of placing a contract through the completion of the project to 
the point of producing, the first complete set of maps will take approximately three years. The project should be ongoing, and updating should be done on a regular basis.

\section{$\underline{\text { Cost }}$}

To gather and assimilate the data approximately $\underline{25}$ man-years will be required. Using an average cost (with G\&A and overhead) of $\$ 80,000$ per year, the manpower costs will be about $\$ 2.0$ million. Supporting costs contain considerable computer usage and travel. These costs will - be approximately $\$ 1.0 \mathrm{million.}$

\subsection{Post Well Drilling Data Analyses for General Correlations}

A tremendous amount of drilling data exist in the oil and gas industry. Within each company these historical data are used to improve future drilling operations. In addition to the specific data gathered for pore pressure and fracture gradient regional mapping, data can be gathered on other aspects of drilling.

\section{Objective}

The primary reasons for gathering past data are twofold. First, the data can be used as a data base for measurements while drilling (MWD). In addition, general correlations relating cause and effect can be constructed on the various aspects of drilling which will indicate the best overall combination of drilling parameters to drill specific wells. Moreover, such data will indicate where the industry needs technology improvements.

Primary considerations will be the development of a methodology for collecting and analyzing data, and the determination of which data are to be collected. 


\section{Schedule}

A project of this magnitude will require several years to organize and follow through to completion of the data collection and management phases. Four to five years will be required as a minimum to do any type of adequate job. The completion synthesis and analyses of various correlations can be done concurrently.

$\underline{\text { Cost }}$

The cost for this project, even if somewhat limited in scope, would be about $\$ 5.0$ million.

Government Role

The government should direct a nonaligned, independent organization to carry out such a project. Possible funding of the project through the SPE or API should be examined.

\subsection{Magnetic Anomaly Data}

State-of-the-Art

Surveying wells using magnetic tools is presently the most accurate method. However, magnetic anomalies exist throughout the United States, especially in the Alaskan area. Additionally, local magnetic anomalies exist in certain areas. The industry would benefit both from a technical and safety point of view if the boreholes could be surveyed more accurately with these magnetic anomalies defined.

Objective

The objective of such a project would be very limited in scope. The work should determine the location of magnetic anomalies (including intensity and variation), how the downhole survey tool accuracy is affected, and how to correct the readings to account for these anomalies. 
Existing data should be collected and, where existing data are insufficient, additional data collected. These data should then be publicly disseminated.

\section{Schedule}

The total project could be accomplished within two years.

\section{Cost}

Approximate costs would be $\$ 500,000$. Extensive work in the Alaskan area could require an additional $\$ 250,000$ to $\$ 500,000$.

Government Role

The government could utilize the USGS or one of the National Laboratories for this project.

\subsection{Drill String Analysis}

\section{State-of-the-Art}

The drill string is an important element in the rotary drilling system. The availability and cost of drill pipe and other elements of the drill string are motivating forces to better understand the downhole behavior of the drill string. However, the problem is technically very difficult, and many years of small incremental technology improvements have henefited the industry.

In recent years, with the advent of high-speed computers and the advances in mechanics, progress has been made toward better understanding the behavior of the drill string.

\section{Government Role}

Since the private industry is undertaking this research and the DOE Division of Geothermal Energy (DGE) through Sandia is funding work at this time, it is recommended that no additional expenditures be made. 
Note: The committee considered this project as medium-high priority with a definite government role. DOE/DGE is working on this problem; there-fore, an assessment of whether that work is applicable to oil and gas drilling must be made, and its success determined, before additional studies are initiated.

\subsection{System Integration Analysis}

\section{State-of-the-Art}

There is no comprehensive, single source of technical information on drilling systems. This impedes improvement in present methods and is a severe handicap to technological progress.

\section{Objectives}

1. Design and fabricate a model for a data base system to incorporate information on any variety of systems or modes of operation pertaining to drilling systems.

2. Define objectives and goals attainable and prioritize items of significance. A basic subset for drilling operations would be:

A. Drilling fluid properties.

B. Comprehensive list of drilling parameters.

C. Factors contributing to and limiting or controlling deviation.

D. Routine analysis, corrections, adjustments, and revisions--i.e., equipment failure, etc.

E. Reservoir parameters, pore pressure detection, shale density plots, estimated fracture gradient, revisions if necessary before drilling.

F. Solids control, shale stability or cause and effect.

G. Well design and modification. . 
3. Integrate into systems as data become available.
A. Test data
B. Lithologic data
c. Electric logging
D. Core analysis
E. Mechanical data
F. Reservoir data
G. Other pertinent data or data to be obtained

4. Incorporate data and evaluate for final analysis.

5. Store for reference, or set up reference library.

Schedule

Approximate cost of this system would be relatively inexpensive once the format was designed and would probably not exceed $\$ 50,000$ per project.

\section{Government Role}

This element is appropriate for government support but received a medium-low priority rating.

\subsubsection{Materials}

3.9.1.4.1 Alternatives to Strategic Materials Used in Drilling for Petroleum or Other Energy Resources

State-of-the-Art

Several of the materials used in drilling for petroleum and other energy resources use metals supplied from sources outside the United States and are subject to curtailed supply because of political or economic. factors beyond the control of the U.S. government or the companies which produce or use these materials. Cobalt-bonded, sintered 
tungsten carbide is the primary material used in carbide-insert premium rock bits, in the hard facing on rock bits and drilling tools, and in the fluid jet nozzles for such tools.

In 1979, the United States imported 90 percent of its cobalt; major sources were Zaire (41), Belgium/Luxembourg (19), Zambia (10), Finland (7), and Canada (5). The only known alternative source is in the metallic mineral nodules on the ocean floor, but an adequate supply from this source is not yet assured. In the event of a supply interruption, high priority for limited supplies of cobalt could go to national defense hardware, since cobalt is extensively used in gas turbine engines and other applications which require exceptional high temperature strength.

In 1979 the United States imported 90 percent of its chromium; South Africa, 44 percent; U.S.S.R., 12 percent; South Rhodesia, 8 percent; and Turkey, 8 percent. Chromium is the principal alloying element in corrosion-resistant steels and some of the hard facing materials used on steel-toothed rock bits and drilling tool cutters, as well as on other surfaces that must resist corrosion and wear on bits and tools.

Tungsten is less critical (59 percent imported in 1979 from Canada, Bolivia, and the Republic of Kored). Tungsten carbide is used in a variety of forms, principally as sintered tungsten carbide or crushed cast tungsten carbide on wear surfaces or for. entire component parts where resistance to abrasive wear and erosive wear is required.

Alternative materials have lower wear resistance or lack required toughness for rock-cutting tools. 


\section{Objective}

Develop and evaluate substitutes or alternatives for cobalt, tungsten, and chromium in rock bits and drilling tools. Develop an alloy/ materials contingency plan for short-and long-term action in the event of supply interruption. Stockpile for minimum needs.

Schedule

Three to five years, plus.

$\underline{\operatorname{Cost}}$

$\$ 1.0$ to $\$ 3.0$ million, plus (stockptle $\$ 10$ s to $\$ 100$ s of millions). Government Role

Cost-sharing with suppliers of corrosion-resistant and wear resistant materials, carbides, and hardfacing materials.

Cost-sharing in laboratory and field test evaluations of candidate substitutes or alternative materials.

Sponsor university and nonprofit organization research on revolutionary solutions to this problem.

\section{Possible Developers}

GE Carbolloy and other carbide suppliers: Stellite Division of Cabot, Chromalloy Corp.; major stainless steel producers: Armco, Crucible, Allegheny Ludlum, Carpenter, etc.

\subsection{High Temperature Elastomers}

State-of-the-Art

The elastomers presently used in sealed bearing rock bits and downhole drilling tools are adequate at normal weights and rotational speeds, and temperatures below $300^{\circ} \mathrm{F}$. Operation at higher temperatures will gradually cause a reduction in seal life. When a temperature of 
approximately $500^{\circ}$ to $600^{\circ} \mathrm{F}$ is reached, it is no longer economically feasible to use elastomeric dynamic seals.

\section{Objective}

To test and develop elastomeric materials to be used in rock bits and other downhole drilling tools which can withstand temperatures in excess of $400^{\circ} \mathrm{F}$ for extended periods of drilling. In the case of rock bits, the life of the seal should equal or exceed the life of the cutting structure.

\section{Schedule}

Four years.

Cost

$\$ 250,000$ per year.

Government Role

The present manufacturers of products which utilize elastomers and suppliers of elastomeric materials and components (seals) could use government aid in "cost-sharing" programs.

\section{Possible Developers}

Major rubber and polymer suppliers, major seal suppliers. University of Akron; Battelle; WRI; LaGuarde Co., Los Angeles.

Sponsor R\&D at universities or nonprofit research institutions to develop revolutionary elastomers to meet industry requirements.

\subsubsection{Instrumentation}

\subsection{Rock Properties from Logs}

State-of-the-Art

The determination of the drilling properties of formations from wireline log information currently includes the following sequence: reviewing available offset logs, (2) selecting the best one or two based 
on proximity and known faulting/formation changes, (3) establish drilling and casing programs based on the offset data, (4) initiate drilling, (5) obtain wireline log of new hole, (6) correlate new log with offset, (7) adjust earlier drilling/casing programs based on . correlation results, (8) drill ahead following new programs, (9) log new section, (10) adjust programs, and (11) drill ahead, etc. Existing logging tech- niques, including the mechanical properties, do not permit satisfactory definition of the various specific mechanical properties of rock forma- tions for use in bit design and/or selection.

Objective

Some fundamental research is needed to find the physical relationship between the mechanical properties of rock types with some characteristic that can be measured by downhole wireline logging. In addition, significant improvements should be realized if the offset log interpretation, drilling, logging, and offset versus new log re-interpretation cycle can be reduced to a computerized data reduction operation. Variations in interpretation due to people skill differences can be minimized. The objective is to develop computer software models to interpret wireline logs to provide useful drilling and production recommendations.

Schedule

Two to five years.

$\underline{\operatorname{Cos} t}$

$\$ 1$ to $\$ 3$ million (very dependent on the researchers starting experience base). 
Government Role

The complexity and basic nature of this problem place's it beyond the capability of industry. In addition, the secrecy of log information between competing operators makes it very difficult for industry to have the needed data base to accomplish the second task. Only the government or an-industry organization (i.e., API) can obtain the needed confidential data.

\subsection{Automatic Drill Pipe Inspection}

\section{State-of-the-Art}

Drill pipe is currently inspected for faults at the pipe yard and in the field. The field inspection involves special equipment and people visiting the rig site. This is an expensive and time-consuming operation that is done when it is convenient to the overall drilling operations or after a serious fishing job has occurred. Present techniques are extremely dependent on individual inspectors' ability for their accuracy. A nondestructive inspection technique developed by Southwest Research Institute for nuclear power piping systems might be modified for drill pipe inșpection.

\section{Objectives}

An inspection technique is needed whereby pipe can be inspected for faults which develop while the pipe is in use during operations. The technique should involve iristrumentation not dependent on specially trained rig hands to check each joint of pipe as it is added to the string during the drilling operation. Also, a system to inspect pipe while tripping is desirable. Adaptability of the Southwest Research developed nondestructive testing technique should be investigated. 
Schedule

One to three years.

$\underline{\operatorname{Cost}}$

$\$ 0.5$ to $\$ 1.5$ million.

Government Role

Note: The committee concluded that this project should have medium-high priority with a government role.

\subsection{Surveying Accuracy}

\section{State-of-the-Art}

The accuracy of survey information, particularly slant-angle bearing (azimuth) is suspect because of magnetic anomalies of the earth, temperature effects on electrical and mechanical devices, intrinsic accuracycreep in gyroscopic devices, the presence of magnetic material, etc., plus the difficulty in verifying the accuracy (or inaccuracy) of a survey once it is run.

\section{Objective}

Develop instruments and techniques to accurately survey boreholes (exact requirements to be determined as part of this task).

Schedule

Two to four years.

Cost

$\$ 2$ to $\$ 3$ million.

Government Role

The USGS is already involved in this area. R\&D work should be performed or funded to provide the needed instrument accuracies for reasons of both ownership (assurance of lease integrity) and safety (permit drilling̣ or ạcouratẹ rẹtief holes). 


\subsection{Downhole/Real Time Data Collection and Analysis}

State-of-the-Art

Some industry work is underway to develop collection and analysis techniques for MWD data once it becomes available. This work is focused on the various company-perceived market segments (i.e., directional drilling, formation evaluation/logging, or drilling efficiency).

\section{Objective}

Provide a centralized and focused effort to bring together a large amount of the downhole information (collected initially in real time while drilling) and to develop the required data interpretation. Data reporting formats must be developed for the various transmission media that are used (i.e., magnetic tape, discs, printed on paper, etc.). These formats would be used by all contributors of data to the central data bank. The interpretation effort would be directed to attain maximum value from the data. This would include safety, survey, logging, and drilling efficiency benefits. The managers of the resulting data base would have an ongoing responsibility to collect and disseminate information.

\section{Schedule}

Three to six years plus ongoing data base management.

$\underline{\text { Cost }}$

$\$ 1.5$ to $\$ 3$ million plus ongoing expenses.

Government Role

Only the government or an industry-wide organization could effectively obtain information considered proprietary by the operators. 


\subsection{Coal Seam Sensor}

State-of-the-Art

Current plans for coal methane drainage and in situ coal processes require survey accuracies and/or seam location to be more precisely determined. Present survey accuracies are marginal at best in azimuth and not adequate to assure the drill is in the coal seam.

Recent efforts by the private sector have reportediy produced a working model, but distribution for widespread use appears to be very slow. Advances in methane drainage, etc., are likely to be delayed by this situation.

Objective

To develop a coal seam sensor to be operated in the wellbore. The initial instrument need not be capable of being in the hole during drilling. Ultimately, real time sensing during drilling will be required.

Schedule

One and one-haif to two years.

Cost

$\$ 200,000$ to $\$ 500,000$.

Government Role

Lack of commercial profitability makes industrial development unlikely. Government financial incentive to industry may promote early availability. The Electrodril concept currently being jointly tested by DUE, General Electric, and industry has the inherent capability of fulfilling this need. 


\subsection{Sensor Concepts}

\section{State-of-the-Art}

Much work is under way in industry to develop and commercialize MWD (data measured downhole while drilling and telemetered to the surface in real time). Companies, such as Schlumberger, NL Industries, Gearheart, and the DOE-funded Teleco, are developing downhole sensors suitable for use while drilling. Virtually all of these efforts are directed at specific measurements that have defined marketability (i.e., directional and formation logging) and low to medium technical risk.

\section{Objectives}

To develop needed sensors for use downhole while drilling that are high risk technically and/or commercially. A short study would be needed to justify current work in the area and to select appropriate measurement- concept candidates. Some example candidates are formation density and acoustic porosity. Both of these measurements are available as wireline log parameters after the hole is drilled. Both are desirable in the while-drilling mode to allow better real time decision-making to improve drilling safety and efficiency, but are technically very difficult to implement in the drilling environment due to high steel mass and noisy environment. Another candidate might be seismic-ahead-of-the-bit which could let a driller "see ahead of the bit."

\section{Schedule}

Candidate selection study, six to nine months; actual research projects, three to ten years depending on number/type selected.

$\underline{\operatorname{Cost}}$

Initial study, $\$ 50$ to $\$ 100,000$; all projects, $\$ 1.5$ to $\$ 7.5$ million. 


\section{Government Role}

Private industry will probably develop suitable sensors eventually, but probably not in the near future. This delay is costly to the exploration and development effort, and it is appropriate that the government encourage an accelerated effort by funding developments in this field.

\subsubsection{Design and Development}

\subsection{Improved Seals}

\section{State-of-the-Art}

High temperatures resulting from the necessary deeper drilling, the use of abrasive mud systems, and an increasing number of dynamic downhole mechanical systems have created a need for improved seals. A rotary shaft seal for high temperature use is probably the most needed develop- ment. Kalorey has demonstrated the excellence of a high temperature static seal, and some graphite seals look promising in turbines. Some seal development work is being conducted for geothermal applications.

\section{Objective}

Develop a reliable, economical, usable seal for temperatures up to $550^{\circ} \mathrm{F}$ and for use in corrosive environments.

Schedule, Government Role, Cost

A small project could summarize recent DOE and industry developments and determine their applicability to fossil energy drilling needs. Laboratory and/or field tesling of a prototype seal could be carried out, if appropriate.

The task to evaluate seal developments would take four months and cost $\$ 10,000$. 
A seal testing task (optional) would take two months (industry participation) and cost $\$ 5,000$.

\subsection{Improved Coring System}

\section{State-of-the-Art}

A pressurized coring system for the retrieval of in situ cores has been developed by DOE and industry. It is reliable for determining the residual oil values needed to design tertiary recovery projects. New bits have demonstrated high penetration rates, and greatly reduced invasion levels have been achieved. The extension of this system to two additional areas is needed. Many primary depleted reservoirs are greatly underpressured, and the use of a foam drililing fluid would lower the hydrostatic head and reduce core washing. Also, it is desirable to evaluate the gas content of Western tight sands and Eastern shales. To achieve this, new core bits are required for the harder rock, and special coring fluids are needed to minimize core invasion. Improved bits for conventional hard rock coring are needed.

\section{Objectives}

Extend the capabilities of pressure coring so that it can be used with lightened fluid columns and modify the system for successful gas saturation measurements.

Schedule, Government Role, Cost

Sandia currently has a project to design a special fluid for gas sand coring; therefore, no effort is required here. A $\$ 50,000$ industry cost-sharing project to develop hard rock core bits and recover cores using a foam drilling fluid will be beneficial. This is a one-year project. 


\subsection{Cementing High Angle Holes}

State-of-the-Art

Inadequate displacement of drilling mud by cement when cementing casing (especially high-angle holes) results in failure to isolate zones and support casing. Various procedures are used; none are 100 percent effective. Additional investigations need to be carried out in: plug flow, (2) turbulent flow, (3) turbulizers, (4) centralizers, (5) mud flush, (6) mud sweep, and (7) cementing packers. The solution to this problem probably revolves around removing cuttings and immobile mud from the low side of the hole and developing a method of centralizing the pipe in the hole. This will require better knowledge of formation com- pressive strength and better centralizer design.

\section{Objectives}

Develop procedures, chemicals, and/or equipment to enable attainment of virtually complete displacement of mud by cement in casing-cementing operations in holes of > 45-degree deviation.

\section{Schedule}

Phase 1: Six months after commencing, build full-scale simulation equipment. Determine in situ compressive strength of various rock types and centralizer standoff force.

Phase 2: 12 months after commencing, complete tests on available chemicals.

Phase 3: 24 months after commencing, complete test on new concepts of mud displacement by cement.

\section{Cost}

Phase 1, $\$ 100,000$; phase 2, $\$ 200,000$; phase $3, \$ 500,000$. 
Government Role

Fund the project on a contract research basis, possibly joint effort with industry.

\subsubsection{Advanced Drilling Systems}

\subsubsection{Electrodri1}

\section{State-of-the-Art}

The "Electrodril" has been a cooperative development of the General Electric Company, DOE, and the petroleum industry. The Electrodril, as developed, to date, provides a method to drill with a downhole electric motor that uses a retrievable power cable and employs a telemetry system which makes downhole measurements of various drilling and safety parameters and transmits them to the surface.

Objectives

The principal objective of the follow-on Electrodril project is to establish the integrity of the system's functional performance by field demonstration testing of all components of the Electrodril system. A secondary objective is to obtain performance parameters of the system to enable evaluation of the economics of Electrodril operation.

Schedule

This project should be completed by the end of FY 83 .

$\underline{\text { Cost }}$

The project costs should be shaped on a 50-percent government involvement basis. The government costs should be $\$ 200,000$ for FY 83 . The system should then be ready for comimercialization.

Government Role

The innovative nature and high risks inherent in Electrodril development justify government involvement on a 50 -percent basis. The 
current phase of work should be completed. The system should then be field tested and evaluated.

\subsubsection{Horizontal Drilling}

State-of-the-Art

Horizontal drilling may be categorized as shallow horizontal drilling, as for utility services, and deep horizontal drilling such as drilling deep inside mines or the horizontal portion of a deep hole starting as a vertical hole at the surface. The present difficulties with horizontal drilling are in guiding the hole direction, making straight holes, cuttings removal, and casing and cementing the holes. Shallow horizontal utility holes are presently drilléd by contractors specializing in such work and will not be considered further in this document. Deep horizontal drilling is considered impractical using present conventional rotary drilling technology. The development of horizontal drilling capability is considered to be a valid area for government-sponsored research because it is a high-risk technology that will probably not be attained by private industrial research investments. When a reliable technique is developed for horizontal drilling, this technology will be utilized in mining applications such as pilot holes for tunnel drifts, ore body investigations, and methane gas drajnage.

\section{Objectives}

The objectives of this project are to develop an economical and reliable sysleill for drilling horizontal holes in soft to hard rocks such as coal, shale and limestone. Such a system would include special bits, downhole motors, jet drilling, a guidance system, instrumentation, and a 
cuttings removal system to reliably achieve horizontal holes in sizes ranging from approximately 4 - to $12 \frac{1}{2}$-inches in diameter.

\section{Schedule}

The schedule for this project is estimated to cover approximately three years. There would be coordination of the instrumentation problem with Section 1.5 of this report. The schedule would include basic technology assessment and then the integration/development of units necessary to achieve a horizontal hole.

Cost

The cost is estimated to be $\$ 1$ million over the 3-year period -with the first year involving approximately $\$ 200,000 ; \$ 350,000$ in the second; and $\$ 450,000$ in the final year.

\section{Government Role}

The government's role is necessary in order to accelerate technology in the areas of unconventional energy resources in order to reduce oil imports. The project will utilize the modular integration of unit/subsystems presently developed, or in the process of development, to assist in achieving project goals.

Developers

Those currently involved include Sandia, METC, LASL, MEI, Conoco, Occidental, Aker Dri11, Dyna-Dri11, etc.

\subsubsection{Jet-Cutting Drilling}

State-of-the-Art

Jet-cutting drilling systems using arrangements of water jets have been in development for several years, sponsored by the Bureau of Mines, DOE, and private industrial firms. These projects have demonstrated 
that high-pressure ( $>50 \mathrm{ksi}$ ) water jets can cut rock at higher rates of penetration than standard conventional rotary bits. The disadvantage of these present jet-cutting systems 1 ies in the hazard of surface handling of the high-pressure, high-fluid volumes required to operate the systems.

\section{Objectives}

The objectives of a jet-cutting drilling system for a drilling project would be:

1. Select a drilling application such as a small (4.0-inch) diameter horizontal drill hole as an application for a jet-cutting system feasibility demonstration.

2. Design a jet-cutting system for the selected application including the jet-cutting bit, drill string, pumps, mud or water supply system, cuttings-collection and handling system.

3. Fabricate, assemble, and test the jet-cutting drilling system.

4. Evaluate the performance of the experimental jet-cutting system. Compare the characteristics of this system with a conventional rotary drilling system.

5. Recommend follow-up investigations of the jet-cutting drilling system.

\section{Schedule}

A relaistic schedule to design, assemble, and test a jet-cutting drilling system to evaluate the feasibility of the system would be two years, assuming that extensive use would be made of jet-cutting principles and hardware already developed by previous investigators. 


\section{$\underline{\text { Costs }}$}

This project development cost should be cost-shared with an industrial company already active in the jet-cutting research field. An arrangement whereby the government would pay for 50 percent of the cost of design, assembly, and testing of the system would be fair and reasonable. A total cost estimate is $\$ 1.5 \mathrm{milli}$ ion of which the government cost would be $\$ 750,000$.

\section{Government Role}

Government participation in this project on a 50-percent costsharing basis is justified because of the high risk associated with unconventional drilling technology.

\subsubsection{Advanced Directional Drilling System}

\section{State-of-the-Art}

Directional drilling in advanced systems may be categorized as high-angle, directional, and horizontal drilling directionally achieved from the surface. The present difficulties in directional drilling with advanced systems encompass various subsystems which are integrated for seam-following drilling including:

-- Control-angle steering sub for trajectory control.

-- Thruster/retractor mechanism to advance the drill string and bit into the formation and for withdrawal.

-- Survey package for determination of bit location, tool face angle, azimuth, and inclination, as well as the rate of angle change and vertical depth.

-- Sensors for determination of bit-weight, drill motor rotary speed, borehole gauge, and formation temperature and pressure. 
-- Logging package for realtime indications of formation properties to allow as-you-go adjustment of drilling plan.

-- Processing and control package for preprocessing of data downhole.

-- Receiver/transmitter unit to provide a communication link between the surface and the drilling system downhole.

-- Drill string wear due to friction in the advancing/retrieving drilling modes including cycle fatigue.

-- Setting casing and cement in highly deviated holes.

Development of directional drilling in advanced system capabilities is considered to be a valid area for government-sponsored research because it is a high-risk technology that will probably not be attained by private industrial research. When reliable techniques are developed for directional drilling, the technology will be utilized in applications for hot-dry rock geothermal and methane drainage from a coal bed. Ongoing big-hole drilling will also benefit from directional drilling improvements.

Objectives

The goal is to enhance development of directional drilling techniques and hardware to facilitate the recovery of energy from unconventlonal energy sources. Specific objectives are:

-- Improve the technology for placement of long-planned path, horizontal, or inclined boreholes (boreholes sizes of 4 to $12 \frac{1}{4}$ inches).

-- Identify, test, and report techniques and hardware for maintaining true, predetermined courses in horizontal boreholes.

-- Identify, evaluate and test compatible equipment for integra- tion into reliable downhole assemblies. 
-- Design and develop an integrated real time directional drilling system for unconventional energy resources.

-- Determine the potential application of such advanced drilling concepts as water and other high pressure erosion concepts.

Schedule

The schedule for this project is estimated to cover from five to seven years. There would be coordination of the instrumentation aspects here with Section 1.5, Instrumentation, in the areas of the seamsensing, downhole real time data collection; and Section 1.3, Drilling System Analysis, in the area of system integration and analysis. The schedule would include technology assessment in the first year, initial integrated system design and analysis in the second year, and research and development in the final years. The research and development would involve development in the third year, the first demonstration (two) and redevelopment in the fourth year, and the second demonstration (two) in the final year.

$\underline{\operatorname{Cos} t}$

The cost is estimated to be $\$ 20$ million over the five- to sevenyear period with the major expenditures occurring in the final three to five years. Year one, $\$ 700 \mathrm{~K}$; year two, $\$ 2200 \mathrm{~K}$; years three, four and five, $\$ 5000 \mathrm{~K}$; and year six, $\$ 2100 \mathrm{~K}$.

\section{Government Role}

The government role is necessary in order to accelerate the technology in the areas of unconventional energy resources to reduce $0 i 1$ imports. The project will utilize the modular/integration of unit/ subsystems presently developed, or in the process of development, to 
assist in achieving project goals. This approach is utilized so a delay in the development of one subsystem will not impede the progress of other subsystems, and will avoid total interdependence of one unit on another.

\section{Developers}

Those currently involved and those who are potential contributors include Sandia, LASL, METC, MEI, Conoco, SOC, Eastman, Dyna-Drill, Terra Tek, Utah Geophysical, Wilson Downhole, etc.

\subsubsection{Environmental Research}

It is important that ecological efforts be considered for any new technology developed. In the drilling industry, this is usually not critical except in the case of chemicals or oilbase muds.

State-of-the-Art

The conventional drilling systems as employed by the petroleum industry have been compatible with the environment except for problems when using oil-base muds. The workshop identified the oil-base mud problems as an industry responsibility.

\section{Objective}

The objective of environmental research is to assess the ecological impact of any new technology developed by DOE. Also, to perform any research necessary to provide ecologically safe access to unconventional or frontier resources.

Schedule

Perform research as necessary.

Cost

$\$ 100,000$ per year. 


\section{Government Role}

Same as described in objective above.

\subsubsection{Safety Research}

Safety, in the concept it is used here, does not concern the personal safety of employees. Certainly that is important, but it is industry's first interest and also falls under the domain of OSHA. The concept here is in the interest of blowout prevention or control and reservoir access.

\section{State-of-the-Art}

On conventional drilling systems, most of the producers and drilling contractors operate at the tope of the art; however, occasional blowouts do occur. Most uncontrolled surface blowouts (as differentiated from a "kick") are the result of human error such as: incomplete well planning or design, improper surface equipment, improper maintenance of detection equipment or, occasionally, poor decisions by inexperienced personnel. Probably the greatest cause of "kicks" or underground blowouts is the lost-circulation problem.

\section{Objective}

The objective of safety research by DOE Deputy Assistant Secretary for 0il, Gas and Shale Technologh should be to:

1. Evaluate ariy new technology developments for safety problems that might preclude deployment.

2. Assist in researching problem areas where the hazards of blowouts, lost circulation, etc., might prevent or delay development of a resource. 


\section{Schedule}

This is to be a continuous mode of preparedness with no defined projects and no budgeted costs. Much work identified in the program. serves the purposes of safety research, e.g., downhole measurements, sensor concepts, etc.

\section{Cost}

No projects defined.

Government Role

The DOE role is the same as discussed in the objective. This is a standby no-cost mode, except to disseminate information to individuals upon request.

\subsection{Drilling Research Projects for Industry Alone}

The workshop drilling group identified and prioritized certain subjects/projects which need to be performed but decided by majority vote that there should be no government role in the work. This section documents those subjects discussed by the workshop participants so that the identified needs will not be lost and they can be used as a guide by industrial researchers. It will be recognized that the authors of some of the following subjects were writing with the expectation that government-sponsored research would be beneficial, and 211 of their remarks regarding governmental research needs may not have been removed. However, all projects in this section were recommended to be the responsibility of the petroleum industry, except in special cases.

A list showing the recognized priority of the following projects is on page 86 . 


\subsubsection{Conventional Technology}

\subsubsection{Fluid Systems}

, 3.10.1.1.1 Solids Control

\section{State-of-the-Art}

Present methods used for solids control include shale shakers, desanders, desilters, hydrocyclones, and centrifuges. Water is also used. Screening, at present, is accomplished through both art and science. The same can be said about the use of hydrocyclones and centrifuges.

\section{Objective}

To find more efficient methods to remove drilled solids from the mud stream. Also, to find more efficient way to mix mud materials and to stir mud surface systems.

\section{Concensus}

Industry should provide this work. The work will continue to be incremental through the product improvement efforts of suppliers.

Cost

Estimates range from $\$ 100,000$ to $\$ 400,000$.

Government Role

The drilling committee concluded that this was a high priority need but no government role.

\subsection{Non-Clay Fluids}

\section{State-of-the-Art}

Various natural and synthetic polymers are in use alone, and in combination, with either commercial (added) clays or naturally occurring clays in the drilled formations. At temperatures above $400^{\circ} \mathrm{F}$, most of the polymers begin to fail to function as viscosifiers and/or filtrate 
control agents. Clays--bentonite/montmorillonite, particularly--may also change in composition and fail to function as filtrate controllers and/or viscosifers at temperatures above $400^{\circ} \mathrm{F}$. Clays can be envisioned as structurally strong bricks or shingles, polymers the mortar that forms the seal that reduces the leakage of filtrate into the formations.

\section{Objective}

To find a "plate-like polymer" that has the structural strength to work either alone or in combination with other polymers to produce a viscusifer/filtrate reducer at high temperatures $\left(600-700^{\circ} \mathrm{F}\right)$.

\section{Concensus}

This project was the highest priority work identified by the drilling committee. No government role was envisioned by the majority, but one reviewer from a major research facility indicated that he did not know of any ongoing research in this area. Another reviewer indicated that this might be an excellent area for some university work.

\subsection{Cuttings Transport}

State-of-the-Art

Cuttings transport in vertical holes is fairly predictable. Cuttings transport in slant holes is not as predictable and proves troublesome. Present research indicates that holes in the $40^{\circ}$ to $50^{\circ}$ slant range are the most troublesome.

In high speed drilling (e.g., large surface holes in Gulf coast regions), cuttings transport capacity increases as penetration rate increases. The competency of the formation becomes a limiting factor in penetration rate. When cutting load density of slurry plus friction loss exceeds competency of the formation, loss of circulation results. 


\section{Objective}

To find ways to transport cuttings out of high-angle holes at a more efficient rate other than by increasing the flow rate. Increasing the flow rate may, at some point, create a problem by generating an abnormal influx of formation in the form of sloughing due to erosion.

Government Role

Cuttings removal was considered a high priority. However, it was the consensus of the committee that, when current research efforts are concluded, no further government effort will be needed. Industry can provide adequate research.

\subsection{Fluid Abrasion}

\section{State-of-the-Art}

Abrasion of the internal surface of the drill string, as well as the mud line, wash pipe, in the swivel and other surfaces connections has not, heretofore, been a problem of any significance. The increasing trend toward drilling larger diameter holes and deeper drilling has created a need for higher flow rates, and abnormal abrasion of internal surfaces is beginning to appear.

\section{Objective}

To find ways to alleviate abrasion of internal surfaces of drill string. Possible avenues of pursuit are larger ID drill pipe and plastic coatings of all internal surfaces of drill fluid circulating system.

\section{Concensus}

The drilling committee concluded that this work was a medium-high priority, but it should be performed by industry with no government participation. 


\subsubsection{Drilling Systems Analysis}

\subsection{Production Damage}

\section{State-of-the-Art}

Permeability damage to hydrocarbon producing and water injection zones in the United States considerably curtails the $0 i 1$ and gas production rates. That is, the rate of production could be increased if formations were undamaged especially in the near wellbore area.

Tremendous technical efforts are spent by the domestic oil and gas industry to increase the production of $0 i 1$ and gas by reducing formation damage.

Since the industry is highly motivated to increase production rates, considerable efforts are expended by the domestic oil and gas industries to solve the problems due to formation damage.

\section{Concensus}

The government should not be engaged in direct research efforts to solve these problems. Most of the major oil companies and suppliers are performing research in this field.

\subsubsection{Materials}

\subsection{Drill Pipe Coatings}

\section{State-of-the-Art}

Polymer coatings for control of corrosion and fluid flow wall friction losses lack the required integrity and/or durability in deep, hot wells which often contain $\mathrm{H}_{2} \mathrm{~S}$ and chlorides in the drilling fluid.

Objective

Evaluate alternative or new candidate coating materials and applications systems that will protect the drill pipe ID surface from chemical reactions with the drilling fluid, while having no adverse effect on 
fluid flow wall friction losses in deep (> 15,000 feet) hot $\left(>200^{\circ} \mathrm{C}\right.$ ) wells where drilling fluids contain $\mathrm{H}_{2} \mathrm{~S}, \mathrm{CO}_{2}$ and chlorides. .

\section{Concensus}

The drilling ocmmittee concluded that this work was low priority and should be performed by private industry with no government participation.

\subsection{High Performance Lubricants for Downhole Tools}

\section{State-of-the-Art}

The lubricants in current journal bearing insert roller bits and sealed bearing roller reamers operate beyond the general state-of-theart in extreme boundary lubrication but are satisfactory for conventional rotary drilling. Operation at higher speeds, with downhole mud motors or turbines, causes a significant loss of useful life in rotating hours or footage drilled compared to conventional rotary drilling. At the higher temperatures encountered in ultra deep drilling, this adverse effect of speed is accentuated.

\section{Project Objective}

Evaluate candidate lubricant materials for high speed (600 to 1000 $\mathrm{rpm}$ ) high temperature ( $>200^{\circ} \mathrm{C}$ bulk lubricant/bearing ambient temperature) operation downhole in sealed journal bearing or roller bearing systems of rock bits and roller reamers. The lubricant, when run with appropriate bearing materials, must provide adequate lubrication for at least twice the lubrication-limited life of current lubricants in such downhole tools and be compatible with the seal materials in the bearing/ seal/lubricant system. Success is contingent upon development of a compatible bearing/seal combination for those conditions. 
Schedule

Two to four years

$\underline{\operatorname{Cos} t}$

$\$ 200,000$ to $\$ 400,000$

Concensus

Adequate commercial incentives are present for this work to be done in the private sector. The government should act as a clearing house for technology from aerospace or other government-related areas applicable to this need.

Probable Developers

Major rock bit suppliers.

\subsection{Alternate Cutting Materials}

\section{State-of-the-Art}

The same discussion as presented in 3.9.1.4.1 of Government Role projects which covers "alternatives to strategic materials" applies here.

Chemical vapor disposition coatings of hard, abrasion-resistant materials on suitable composite substrates having compatible physical and mechanical properties, such as $\mathrm{TiB}_{2}$, presently lack the abjlity to withstand gouging abrasive wear on rock cutting surfaces; however, they may be suitable for erosion or rubbing abrasion resistance on downhole tools. Metal glasses may provide the required combination of hardness and fracture toughness but cannot be produced in suitable forms for rock cutting tools. Cermets or ceramics in a composite material could conceivably be used if adequate mechanical properties can be obtained. 
Polycrystalline diamond (manmade) has very high abrasive-wear resistance but is not currently produced in tooth or insert shapes suitable for rolling-cone-type rock-cutting tools. PDC-type bits have proven feasible and are commercially available.

Schedule

Three to five years

$\underline{\text { Cost }}$

$\$ 2: 0-\$ 4.0$ million

Concensus

The drilling committee decided this was a low priority project and that it should be performed by industry.

\subsection{Corrosion-Related Materials Problems}

\section{State-of-the-Art}

Deep hole drilling sometimes encounters $\mathrm{H}_{2} \mathrm{~S}$ and the water base drilling mud contains $\mathrm{Cl}, \mathrm{CO}_{2}, \mathrm{O}_{2}$, and $\mathrm{SO}_{4}$. These constituents, in conjunction with the elevated temperatures downhole, cause severe corrosion, loss of fatigue strength, stress, corrosion cracking and sulfide stress cracking. (Sulfide cracking is suppressed at high downhole temperatures, but it is a severe problem at lower temperatures encountered at shallower depths or during tripping.) At greater depths, the higher strength steels required in drill pipe, drill collars, downhole tools, and casing makes them more susceptible to sulfide stress cracking, stress corrosion cracking, and corrosion fatigue cracking. The total market for the special materials required in deep hole drilling is sma11, by manufacturing standards, and is not sufficient to justify high levels of R\&D investment by the suppliers of these special materials and tools. R\&D is needed to assure timely solutions to these problems. 


\section{Project Objectives}

Create and evaluate candidate materials having the following characteristics:

1. Yield strength, tensile strength, and bending or axial tension/ tension fatigue strength in typical deephole drilling environments that exceed the strength levels of current materials by at least 20 percent.

2. Corrosion rates under typical deep downhole conditions that are at least 50 percenti.less than for current materials.

\section{Concensus}

A majority of the drilling committee decided this project was high priority but that government research should not be involved. However, one DOE project, which studies stress-induced corrosion, is currently ongoing at Tulsa University.

Possible Industry Roles

Perform alloy development and testing (laboratory and field tests) of candidate materials.

Sponsor R\&D at universities and nonprofit research institutions on alloy development, or novel approaches to these problems. Sponsor university research on basic causes of corrosion-related embrittlement or loss of strength in deep downhole environments.

Possible Developers

Southwest Research Institute

Ohio State University

MIT

Lehigh University

Case Wostcrn Reserve University 
Battelle, IITRI, etc.

Major Steel Suppliers

INCO

Climax Molybdenum Co. (AMAX)

\subsubsection{Instrumentation}

3.10.1.4.1 Downhole MWD/Logging

State-of-the-Art

Much work is currently being done by industry to develop downhole sensors, data transmission links, and surface data presentation equipment. Some work is also under way to interpret the information as it is received in real time. Sensor research and interpretation efforts are focused on drilling parameters and logging parameters. The total value of downhole information will not be realized until meaningful, effective interpretation techniques and a completed sensor suite are developed and in use by industry.

\section{Objective}

Develop specialized sensors to complement sensors currently under development in industry. High-risk devices might include downhole, while drilling, seismic ahead of the bit. A part of this project would be to evaluate all ongoing sensor work and determine specific needs not being addressed. Another part of this project is to provide a concentrated effort to compile the interpretation work from industry, disseminate this compilation result to industry, evaluate the compilation result, and provide additional interpretation effort where needed. Major benefit: should shorten the time it normally takes industry to fully capture the benefit of new technology by one half. 
Schedule

Two to five years with possibilities of stretching to ten years. $\underline{\operatorname{Cos} t}$

$\$ 250,000$ for survey of current work and up to $\$ 7.5-\$ 10 \mathrm{milli}$ ion for actual R\&D.

\section{Research Role}

Note: Committee concluded a medium-high priority with no further need for government research except in sensors concepts. However, secrecy of $\log$ iriformation between competing operators makes it very difficult for industry to have the needed data base to accomplish this task. Only the government or an industry organization (i.e., API) can obtain needed confidential data.

\subsubsection{Design and Development}

\subsection{Improved Bits}

\section{State-of-the-Art}

Roller cone and conventional diamond drill bits have been developed to a high degree of technology mainly through empirical experimentation. It is unlikely that large increases in performance capabilities can be made. This is especially true for drilling rocks that have a high degree of fracture toughness such as those under high hydrostatic pressure (e.g., deep oil/gas drilling). Development and understanding of polycrystalline compact (PDC) drag bits, hydraulically aided bits, percusston bits, or other similar devices have not progresscd to a sufficient level for widespread usage.

Development of PDC bits has been going on for several years. The work initially centered on developing attachment techniques for the PDC. 
The work is now expanding in scope to include: (1) rock-cutter interaction studies, (2) wear mechanism analysis, (3) cutter failure modes, and (4) overall bit design concepts.

\section{Objective}

The objective of a DOE project in this area would be to spur the development of improved bits by continuing present research work.

\section{Schedule and Research Role}

Sandia Laboratories has served as a prime DOE contractor in the development of PDC bits. Work should continue in this area to develop technology and expedite its transfer to industry. A prime goal should be to integrate the results of single research experiments into a usable criteria to aid bit design. The bit industry is, and should continue, pursuing these developments with major emphasis on bit design and field testing. Research into cutter design, placement, wear mechanisms, and other isolated ?laboratory type analysis could be producing usable results ino, three months and continue productivity for a year. Some major bit design philosophies could be substantiated within six months. Industry/ DOE combination projects to design and develop bits could be useful.

Note: The drilling committee noted a medium priority with no further government research. After existing contracted efforts are completed, the effort for $0 i 1$ and gas drilling can be reevaluated and possibly terminated. It should be pointed out that the bits needed by the DOE/Geothermal Division are unique arid their efforts may need to be continued. 
Needs

Reliable bits for hard rock.

High-speed bits compatible with turbines.

Bits for directional drilling.

Cost

$\$ 200,000$ for one year

$\$ 500,000$ for two-year program with industry shared designs and tests.

\subsection{We11 Bore/Cement/Casing/Design}

\section{State-of-the-Art}

Serious casing-stability problems arise from lack of considering the total "system" as a unit: well bore-cement-casing. Buck1ing, rupture, and nonsupport of the casing are frequent occurrences. Partial solutions to the general well bore stability and casing stability calculations can be made on vertical-to-low deviation holes. Complete cement sheaths can usually be obtained on near-vertical holes.

\section{Objective}

Develop information, equipment, and procedures that will provide a "permanent," utilitarian steel conduit for "working in" or producing fluids from the reservoir to surface.

Schedule

Well bore stabilization: Use oil, mud, or equivalent cementing procedures, etc., to be developed in item 3.9.1.6.3, page 113 .

Casing: Develop information and procedures to calculate casing stability in high-temperature, deviated holes.

Use competent consultant (ramely Chetham, Rice Univ.), 12 calendar months (six montlis) required. 
Cost

Time and equipment: $\$ 150,000$.

Government Role

The drilling committee concluded this to be a low priority project with no government role.

\subsection{Directional Drilling Systems}

State-of-the-Art

Directional drilling systems are a complex combination of specific elements such as bits, motors, kick-off tools and procedures, surveying, steering, etc. Using these elements to direct a borehole to a specified target is frequently an "art" as performed by directional drillers.

Systems improvements as a whole occur when developments are made in these elements individualiy, or when they are structured together in a way that synergistically contributes to the overall process. Conventional requirements include better accuracy in placing the borehole in the desired location (this includes relief well drilling), avoiding intersections between wells on densely populated platforms, reaching lateral locations of increased displacement, and developing methods for real time steering techniques.

\section{Objective}

Coordinate and utilize developments in individual systems elements to produce an improved directional drilling system.

Schedule/Cost/Government Role

Directional drilling needs for extended reach drilling and improved accuracy are the principal tasks. 


\section{Tasks}

1. Develop improved system components. Cost: $\$ 1$ million over three years.

2. Coordinate and extend reach drilling program.

\section{Concensus}

The majority of the drilling committee concluded that this was a medium-high priority project but should be performed by industry without government participation. However, DOE is performing some work for special applications and there will probably be some technology "fallout" for the oil and gas industry.

\subsubsection{Advanced Drilling Systems}

\subsubsection{Flexible Drill String Drill}

\section{State-of-the-Art}

The concept of a drilling system using a flexible drill string has been developed in France by the organization IFP, a French government agency. IFP has worked on a flexible drill string system for approximately 20 years: IFP has recently approached U.S. major drilling hardware manufacturers to develop a U.S. marketing outlet, with no apparent success. The flexible drill string concept as developed by IFP would use a downhole motor such as a turbodrill or it could use an Electrodril. The principal advantage claimed by the IFP system is to eliminate string handling problems associated with tripping. Downhole instrumentation can be easily incorporated in the system; therefore, MWD systemlis can be integrated into the system. Automatic drilling is possible with the system. 


\section{Objective}

The objective of the project is to demonstrate the feasibility of. the flexible drill string system.

Schedule

This project should be completed in one fiscal year.

$\underline{\text { Cost }}$

This project should be cost-shared with the French agency IFP providing the flexible drill string system components and the government funding the field tests of the system. The total costs to the government is estimated to be $\$ 1.5$ million for the entire field test program.

\section{Concensus}

The drilling committee concluded the lowest priority on the basis that it will eventually be available in the united States. No government work will be initiated.

\subsubsection{Deep Fluid Motor (for Deep Drilling)}

\section{Background}

Deep drilling frequently results in a need for a downhole motor having the capability of drilling under extreme conditions of temperature and pressure. Deep drilling frequently occurs with some directional drilling, which requires a downhole motor to effect a change in direction. A downhole motor also results in less wear on the drill string and casing since the wear and string fatigue associated with rotation is eliminated. Existing fluid motors use elastomers and seals which cannot withstand the high pressures, >10 ksi, and temperatures, > $200^{\circ} \mathrm{C}$, associated with deep holes. For geothermal hot dry rock drilling, a high temperature turbodrill was developed by Maurer. 
Engineering Inc., Houston, Texas, and four units were purchased by Los Alamos Scientific Laboratory and used on the hot dry rock geothermal project to directionally drill holes to 15,000 feet and $300^{\circ} \mathrm{C}$. The reliability of these turbodrills was satisfactory, but a great deal of improvement in operating characteristics and performance is possible. Another turbodrill capable of operation in deep high temperature holes has been marketed by Dyna-Drill, a division of Smith International.

\section{Objectives}

The objectives of this project are to upgrade the capabilities and performance of the fluid motors and turbodrills presently marketed commercially in the United States. This would be done by developing performance specifications which would define the hostile environment operating conditions of pressure, temperature, operating speed range, time on bottom, etc., and would invite the manufacturers to furnish products for test and evaluation. The manufacturers would be invited to include in their systems downhole instrumentation to measure temperatures, rotary speed, bit weight, and seal condition.

Schedule

This project should extend over three fiscal years.

$\underline{\text { Cost }}$

This project should be cost-shared with the motor/turbine manufacturers. The government should buy the off-the-shelf hardware and instrumentations systems and should finance the development of special instrumentations systems. The government should finance the cost of field tests of the deep fluid motor drilling systems. The total cost to the government is estimated to be $\$ 3.0 \mathrm{million}$. 


\section{Government Role}

The government role should be to encourage the upgrading of existing motor/turbine systems by financing the extensive instrumentations required on this project and to finance the test program required to evaluate the systems. The government should emphasize the cost sharing aspects by encouraging the turbodrill manufacturers to upgrade their product capabilities by incorporating adequate seals, bearings, and instrumentation modifications.

\section{Concensus}

The drilling committee corcluded a medium-high priority but no government role; however, this type work has been needed for geothermal development and will probably be performed by the DOE Division of Geothermal Energy.

\subsubsection{Safety}

\subsubsection{1 $\cdot \mathrm{H}_{2} \mathrm{~S}$ Detection}

\section{State-of-the-Art}

The present method of $\mathrm{H}_{2} \mathrm{~S}$ detection is through the use of instruments, at ground level, which analyze the amount of gas in the drilling fluid by use of a gas chromatograph.

\section{Objective}

The objective is not only to improve the method and reliability of $\mathrm{H}_{2} \mathrm{~S}$ detection at the surface but to be able to more quickly ascertain the severity of the gas, especially at greater depths. This would necessitate the use of sophisticated sensing equipment in the drill string and/ or the bit. A method must then be developed to quickly and accurately transmit the information to the surface. 
Schedule

Three to four years

$\underline{\text { Cost }}$

$\$ 100,000-\$ 200,000$

Concensus

The feasibility of this proposal over the present method is questionable. The drilling committee concluded that this is a low priority project and should be accomplished by industry. No government work is expected.

\subsubsection{Environmental}

\subsubsection{0il/Water Separation}

Description

Many, many, many procedures have been used to separate oil from water:

o hay

o "oil sop"

o gravity separation

-- time

-. centrifugal

-- skimmers

-- flotation cells - both with and without air injection

- bacterial consumption of $0 i 1$

- oil dispersion (not really separation).

All work to a degree; many are very effective (namely, flotation cells). However, none reduces oil content to below $50 \mathrm{ppm}$ consistently (reliably). 


\section{Objective}

Reduce oil content of water to below $50 \mathrm{ppm}$ on a consistent basis.

Schedule

Two to four years.

$\underline{\operatorname{Cos} t}$

$\$ 500,000$ to $\$ 2$ million.

Concensus

The drilling committee concluded that this was a medium-low priority with no government role. It should be performed by private industry.

\subsubsection{Cuttings Cleaning (0i1 Mud)}

\section{Description}

The inadequate removal of oil from oil-mud cuttings has severely limited the use of oil muds, especially in offshore operations. In many geographical areas it is not economic (if not impossible) to drill with water muds. Although no satisfactory methods exist, many procedures are used with varying degrees of effectiveness:

$0 \quad$ retorting oil from cuttings

o burning oil from cuttings

- o fluidized-bed removal of oil

0 washing of cuttings

-- with water

-- with detergent

-- with diesel oil

o pelletizing "mulled" cuttings with gravity settling 
Objectives

Develop or refine procedures to render oil-mud cuttings environmentally acceptable.

Schedule

Complete work in one year.

$\underline{\text { Cost }}$

$\$ 500,000$ ( $\$ 300,000$ personnel; $\$ 200,000$ equipment).

Government Role and Concensus

The majority of the drilling committee found, this project to be of very high priority but recommended no government role; however, some members strongly emphasized their belief that government should perform some of this research. The main reason for the no-government-role opinion was because all major companies and suppliers have been searching for solutions for several years. 
BIBLIOGRAPHY OF PREVIOUS PLANNING DOCUMENTS

In the preparation of the introductory sections of this document, either excerpts or implied content has been taken from the materials listed below. Their original purpose was for the management or development of a detailed, comprehensive program for either drilling, offshore or Arctic research.

\section{Title}

Findings of National Research Council Ad Hoc Committee on Technology of Drilling for Energy Resources

Annual Drilling R\&D Expenditure in the $0 i 1$ \& Gas Industry

Blueprint for a Comprehensive Federal Drilling Technology Development Plan w/Appendix A

IBID - Appendices B, C, \& D

Drilling R\&D Strategic Plan Data Base: Vol. I - Technology Assessment

IBID: Vol. II - Resource Assessment

IBID: Vol. III - Drilling Technology Diffusion

IBID: Vol. IV - Industry Base Case

A Development Plan for Drilling Technology - Draft Copy

Program Implementation Plan for Drilling R\&D - Draft Copy

A Strategy for Offshore Technology Research \& Development (Includes Arctic)

Report of the Workshop on Arctic $0 i 1$ and Gas Recovery
Author or Contractor \& Date

NRC Committee June 1975

Spears \& Associates, Inc. November 1977

Williams Bros. Engineering Co. February 1978

Williams Bros. Engineering Co. February 1978

Booz-Allen \& Hamilton, Inc. March 2, 1979

February 28, 1979

March 2, 1979

March 27, 1979

Jeff Smith, et al March 6, 1979

Livesay Consultants November 6, 1979

Energy Interface Assoc., Inc. May 1980

W. A. Sackinger, Geophysical Institute September 1980 
Project Plan Document for the Unconventional Gas Recovery Drilling Technology Project FY-81
Morgantown Energy Technology Center (METC)

December 1980

Most of the above items are not publicly available except (in some cases) through the Technical Information Center contract files. Copies can be obtained from the DOE HQ, Deputy Assistant Secretary for 0i1, Gas and Shale Technology, or from C. Ray Williams, Project Manager, Drilling, Offshore and Arctic Technology, Bartlesville Energy Technology Center, Bartlesville, Oklahoma. 


\section{UNITED STATES DEPARTMENT OF ENERGY}

BARTLESVILLE ENERGY TECHNOLOGY CENTER

P.O. BOX 1398

BARTLESVILLE, OKLAHOMA 74005

POSTAGE AND FEES FAID

OFFICIAL BUSINESS

UNITED STATES
DEPARTMENT OF ENERGY

PENALTY FOR PRIVATE USE, $\$ 300$ 